\title{
The intriguing regulators of muscle mass in sarcopenia and muscular dystrophy
}

\author{
Kunihiro Sakuma ${ }^{1}$, Wataru Aoi $^{2}$ and Akihiko Yamaguchi ${ }^{3}$ \\ ${ }^{1}$ Research Center for Physical Fitness, Sports and Health, Toyohashi University of Technology, Toyohashi, Japan \\ ${ }^{2}$ Laboratory of Health Science, Graduate School of Life and Environmental Sciences, Kyoto Prefectural University, Kyoto, Japan \\ ${ }^{3}$ Department of Physical Therapy, Health Sciences University of Hokkaido, Kanazawa, Japan
}

\section{Edited by:}

Luciano Merlini, Istituto Ortopedico

Rizzoli IRCCS, Italy

Reviewed by:

Guo-Yuan Yang, Shanghai Jiao Tong

University, China

Fabio Demontis, St. Jude Children's

Research Hospital, USA

*Correspondence:

Kunihiro Sakuma, Research Center for Physical Fitness, Sports and Health,

Toyohashi University of Technology,

1-1 Hibarigaoka, Tenpaku-cho,

Toyohashi 441-8580, Japan

e-mail: ksakuma@las.tut.ac.jp
Recent advances in our understanding of the biology of muscle have led to new interest in the pharmacological treatment of muscle wasting. Loss of muscle mass and increased intramuscular fibrosis occur in both sarcopenia and muscular dystrophy. Several regulators (mammalian target of rapamycin, serum response factor, atrogin-1, myostatin, etc.) seem to modulate protein synthesis and degradation or transcription of muscle-specific genes during both sarcopenia and muscular dystrophy. This review provides an overview of the adaptive changes in several regulators of muscle mass in both sarcopenia and muscular dystrophy.

Keywords: sarcopenia, muscular dystrophies, autophagy, myostatin, serum response factor, mTOR

\section{INTRODUCTION}

In humans, skeletal muscle is the most abundant tissue in the body, comprising $40-50 \%$ of body mass and playing vital roles in locomotion, heat production during periods of cold stress, and overall metabolism. Skeletal muscle is composed of bundles of muscle fibers called fascicles. The cell membrane surrounding the muscle cell is the sarcolemma, beneath which lies the sarcoplasm, which contains the cellular proteins, organelles, and myofibrils: the titin actin filament and the thicker myosin filament. The arrangement of these protein filaments gives skeletal muscle its striated appearance. Skeletal muscle is capable of remarkable adaptations in response to altered activity. These adjustments to mechanical and metabolic demands elicit marked modifications of gene expression that could lead to gain (hypertrophy) or loss (atrophy) of muscle mass. Whereas, endurance training leads to minor changes in skeletal muscle mass, strength training induces marked hypertrophy of exercising muscles. Resistance training [full squat, leg press, and leg-extension, three sets to failure of $6-8 \mathrm{RM}(\sim 80-85 \%$ of the 1 RM, Monday) and $10-12$ RM ( $70-75 \%$ of the 1 RM, Friday), 18 weeks] for young sedentary subjects (women, 21.4 \pm 1.4 -year old) elicited a $10-30 \%$ increase in fiber cross-sectional area of the vastus lateralis muscle (Staron et al., 1991).

Loss of muscle is a serious consequence of many chronic diseases and of aging itself because it leads to weakness, loss of independence, and increased risk of death. Unfortunately, the field suffers from having more definitions than therapies; muscle wasting is an inevitable part of aging, where it is known as sarcopenia (Rosenberg, 1989). Muscle loss is also common in muscular dystrophy, in which markedly loss of various membranous structural proteins occurs around muscle fibers (Vainzof et al., 2008). Intriguingly, sarcopenia and muscular dystrophy possess similar characteristics, including the accumulation of fibrosis, a wide-range fiber size distribution, and central nuclei (Sakuma et al., 2008; Vainzof et al., 2008; Berger and Doherty, 2010; Hepple, 2012).

In hypertrophied muscle, increasing protein synthesis and decreasing protein degradation are also important events. Phosphatidylinositol-3-kinase (PI3-K)/Akt/mammalian target of rapamycin (mTOR) signaling has been shown to be crucial to protein synthesis (Glass, 2010; Sakuma and Yamaguchi, 2012b). Mechanical stretching in vivo and in vitro activates serum response factor (SRF)-dependent signaling in skeletal muscle (GauthierRouviére et al., 1996; Sakuma and Yamaguchi, 2012a). In contrast, negative regulators are proposed to induce muscle atrophy by inhibiting protein synthesis and enhancing protein degradation in skeletal muscle. For example, the ubiquitin-proteasome system (UPS) is thought to be a major contributor for degrading many structural proteins (Cao et al., 2005). However, the autophagylysosome system has been largely ignored despite evidence that lysosomal degradation contributes to protein breakdown in atrophying muscles (Furuno et al., 1990). Sandri $(2010,2011)$ has shown that the autophagy-lysosome and UPS are coordinately regulated during muscle wasting. On the other hand, myostatin is a potent inhibitor of muscle growth and is considered as a therapeutic target for muscle wasting including cachexia and sarcopenia, muscular dystrophy, and amyotrophic lateral sclerosis (Sakuma and Yamaguchi, 2011b).

Several positive and negative regulators (mTOR, SRF, atrogin1 , p62, and myostatin) have been proposed to enhance protein degradation or transcription of muscle-specific genes during both sarcopenia and muscular dystrophy. However, the adaptations of these important mediators were not necessarily similar in these 
two conditions. Muscle ring finger 1 (MuRF-1), an E3 ubiquitin ligase, is activated in many different types of muscular dystrophy (Saenz et al., 2008; Fanin et al., 2013, 2014), but many mediators of UPS do not change during sarcopenia (Sakuma et al., 2014). Several studies have indicated similar dysfunctions of autophagic signaling during sarcopenia and muscular dystrophy (De Palma et al., 2012; Sakuma et al., 2014). In addition, skeletal muscle in both conditions exhibits down-regulation of SRF (Sakuma et al., 2004, 2008) and appears to show the activation of myostatindependent signaling (Sakuma et al., 2004; McKay et al., 2012). In contrast, the adaptation of mTOR-dependent signaling seems to differ between sarcopenia and muscular dystrophy to some extent (De Palma et al., 2012; Sakuma et al., 2014). To build on these previous findings, more descriptive and comprehensive comparison of positive and negative muscle regulators between sarcopenia and muscular dystrophy is needed.

Therefore, in this review, we concentrate on specific alterations discussed in the recent literature that are present in the skeletal muscle in both muscle wasting disorders. In addition, we focus on the adaptive changes in positive and negative regulators (mTOR, UPS, autophagy, etc.) of muscle mass. If we can understand more concretely and definitively the mechanisms underlying sarcopenia and muscular dystrophy, more effective applications (nutritional and/or pharmacological) for skeletal muscle wasting may be conducted in the near future.

\section{CHARACTERISTICS OF SARCOPENIA AND MUSCULAR DYSTROPHY \\ SARCOPENIA}

Aging is associated with a progressive decline of muscle mass, quality, and strength, a condition known as sarcopenia (Candow and Chilibeck, 2005). Although this term is applied clinically to denote loss of muscle mass, it is often used to describe both a set of cellular processes (denervation, mitochondrial dysfunction, inflammation, and hormonal changes) and a set of outcomes such as decreased muscle strength, mobility, and function (Melton et al., 2000), a greater risk of falls, and reduced energy needs. von Haehling et al. (2010) have estimated its prevalence at 5-13\% for elderly people aged $60-70$ years and $11-50 \%$ for those aged 80 years or above. Lean muscle mass generally contributes up to $\sim 50 \%$ of total body weight in young adults, but declines with aging to $25 \%$ at $75-80$ years of age (Short et al., 2004). The loss of muscle mass is most notable in the lower limb muscle groups, with the cross-sectional area of the vastus lateralis being reduced by as much as $40 \%$ between the ages of 20 and 80 years (Lexell, 1995). At the muscle fiber level, sarcopenia is characterized by specific type II muscle fiber atrophy, fiber necrosis, and fiber type grouping (Lexell, 1995).

Several possible mechanisms for age-related muscle atrophy have been described.

In a recent review by Demontis et al. (2013a) provides indepth comparison of sarcopenia in Drosophila and mammals. Both muscles include very similar age-related changes such as increased mitochondrial dysfunction, decreased function of autophagy/lysosome system, increased apoptosis, and protective role of dietary restriction. In contrast, aged Drosophila and mammalian muscles exhibit several differential characteristics (endocrine changes, decreased regenerative capacity via satellite cells, defects in $\mathrm{Ca}^{2+}$ homeostasis, and increased fiber atrophy). Age-related muscle loss is a result of reductions in the size and number of muscle fibers, possibly due to a multi-factorial process that involves physical activity, nutritional intake, metabolic homeostasis, oxidative stress, hormonal changes, and lifespan (Baumgartner et al., 1999; Roubenoff and Hughes, 2000; Demontis et al., 2013b). The specific contribution of each of these factors is unknown, but there is emerging evidence using rodent muscle that the distribution of several positive regulators (Akt and SRF) of muscle hypertrophy with age is an important feature in the progression of sarcopenia (Sakuma and Yamaguchi, 2010, 2011a). Very intriguingly, more recent studies indicated an apparent functional defect in autophagy- and myostatin-dependent signaling in both mice and human sarcopenic muscle (Wohlgemuth et al., 2010; McKay et al., 2012; Zhou et al., 2013). In contrast, many investigators have failed to demonstrate age-related enhancement in the levels of common negative regulators [atrophy gene-1 (atrogin-1), NF-кB, and calpain] in senescent mammalian muscles (Sakuma and Yamaguchi, 2011a, 2012c). Currently available data show that human sarcopenia is attenuated by resistance training, the ingestion of amino acids, and treatment with testosterone (Sakuma and Yamaguchi, 2011a, 2013b; Wakabayashi and Sakuma, 2014). In addition, myostatin signaling inhibition for mice and calorie restriction for mice and rhesus monkey have been shown to counteract sarcopenia (Sakuma and Yamaguchi, 2011a, 2013b). Among this, resistance training in combination with amino acidcontaining nutrition is the best candidate to attenuate age-related muscle wasting and weakness in human.

\section{MUSCULAR DYSTROPHY}

The neuromuscular disorders are a heterogeneous group of genetic diseases, causing progressive loss of motor ability. More than 30 genetically defined forms are recognized, and in the last decade, mutations in several genes that result in the deficiency or loss of function of various important muscle-proteins have been reported. These include dystrophin, sarcoglycans (SG), and dysferlin, which are sarcolemmal or peri-sarcolemmal proteins; $\alpha 2$-laminin and collagen VI, which are extracellular matrix proteins; and emerin and lamin $\mathrm{A} / \mathrm{C}$, which are nuclear proteins.

Defects in components of the dystrophin-glycoprotein complex (DGC) are known to be an important cause of different forms of muscular dystrophy (Yoshida and Ozawa, 1990; Ervasti and Campbell, 1993). The DGC is an oligomeric complex that connects the subsarcolemmal cytoskeleton to the extracellular matrix. It consists of dystroglycan ( $\alpha$ - and $\beta$-DG), SG, and syntrophin/dystrobrevin subcomplexes. Mutations in the dystrophin gene cause the most common form of X-linked Duchenne muscular dystrophy (DMD) (Hoffman et al., 1990). The sarcoglycan sub-complex is also linked to $\beta$-DG and includes $\alpha$-SG, $\beta$-SG, $\gamma$-SG, and $\delta$-SG, which are tightly associated and inserted into the membrane. Mutations in the genes coding these four SG proteins cause severe forms of limb-girdle muscular dystrophies types LGMD2D, 2E, 2C, and 2F, respectively. $\alpha$-DG, a receptor for the heterodimeric basement membrane protein laminin-2, binds to $\beta$-DG. Mutations in the LAMA2 gene, encoding the $\alpha 2$ chain of 
laminin-2, cause $\alpha$ 2-laminin deficiency and a severe form of congenital muscular dystrophy (CMD1A) linked to chromosome $6 \mathrm{q}$ (Helbling-Leclerc et al., 1995). Other milder forms of muscular dystrophy are caused by mutations in genes coding the enzyme calpain 3 (LGMD2A), the sarcolemmal protein dysferlin (LGMD2B), and the sarcomeric protein telethonin (LGMD2G) (Vainzof et al., 2008).

Sarcopenia and muscular dystrophy possess several similar characteristics as pointed out in more recent review by Rudolf et al. (2014). Fiber size variability is a major feature of various muscular dystrophy (Engel and Ozawa, 2004; Taniguchi et al., 2006; Krag et al., 2011), although it is frequently observed in sarcopenic mammalian muscles (Berger and Doherty, 2010; Hepple, 2012). The occurrence of small fiber groups was reported for samples from Becker muscular dystrophy (BMD) and DMD (ten Houten and De Visser, 1984; Engel and Ozawa, 2004), whereas elderly muscle exhibits extensive fiber type grouping (Kanda and Hashizume, 1989; Andersen, 2003). Rudolf et al. (2014) also indicated coexpression of multiple myosin heavy chain isoforms in these two muscles (Marini et al., 1991; Patterson et al., 2006). Furthermore, both muscles exhibit centralized nuclei, and the accumulation of fibrosis and intramuscular adipocyte. Although the exact reason for such a similarity has not been precisely elucidated, it seems to be feasible to apply same therapeutic approaches to sarcopenia and muscular dystrophy.

\section{PHOSPHATIDYLINOSITOL-3-KINASE/Akt/MAMMALIAN TARGET OF RAPAMYCIN}

A central pathway involved in hypertrophy is regulated at the translational level by the serine/threonine kinase Akt. In muscle, Akt is activated by the upstream PI3-K, induced either by receptor binding or by integrin-mediated activation of focal adhesion kinase (FAK), such as in cardiac myocytes (Sakamoto et al., 2002). The striking effect of Aktl on muscle size was demonstrated by the transient transfection of a constitutively active inducible Aktl transgene in skeletal muscle in vivo (Lai et al., 2004). In addition, muscle mass was completely preserved in denervated transgenic Akt mice (Pallafacchina et al., 2002). Possible downstream regulators of Akt, mTOR, and glycogen synthase kinase (GSK)-3 $\beta$, play a crucial role in the regulation of translation.

Mammalian target of rapamycin exists in two functionally distinct multi-protein signaling complexes, mTOR signaling complex (mTORC) 1 and mTORC2. Akt activates mTOR via phosphorylation and inactivation of tuberous sclerosis complex (TSC)-2. In general, only signaling by $\mathrm{mTORC} 1$ is inhibited by rapamycin, and thus the growth regulatory effects of rapamycin are believed to be primarily exerted through the mTORC1 complex (Zoncu et al., 2011). It is now widely accepted that signaling by mTORC1 is involved in the regulation of several anabolic processes including protein synthesis and ribosome biogenesis, as well as catabolic processes such as autophagy (Zoncu et al., 2011). In skeletal muscle, signaling by mTORC1 has been shown to be regulated by a variety of different stimuli that control skeletal muscle mass. For example, signaling by mTORC1 is activated in response to hypertrophic stimuli such as increased mechanical loading (mechanical overloading for the plantaris muscle of mice by surgical ablation), feeding, and growth factors (Bodine et al., 2001b; Drummond et al., 2009).

Since signaling through $\mathrm{PI} 3-\mathrm{K} / \mathrm{Akt}$ can regulate mTORindependent growth regulatory molecules such as GSK-3 $\beta$, tuberin (TSC-2), and the forkhead box $\mathrm{O}$ (FOXO) transcription factors (Sandri, 2008), it was not clear whether signaling by mTORC1 is sufficient, or simply permissive, for the induction of hypertrophy. For example, Hornberger et al. (2003) found that stretch-induced activation of mTOR signaling was not abolished in the skeletal muscle of Akt1-/- mice. Furthermore, Akt-independent stimulation of mTOR may be positively or negatively regulated by phosphorylation of TSC-2. For instance, TSC-2 is inhibited by FAK in 293T cells (Gan et al., 2006), suggesting that up-regulation of FAK expression with increased mechanical loading for skeletal muscle could stimulate protein synthesis via TSC-2 inhibition. All these regulatory influences may explain the rise in the level of phosphorylated p70S6K (Coffey et al., 2006). Therefore, mTOR is currently thought to be the major hub for the integration of an array of upstream signaling pathways that, when activated, ultimately result in increased translational efficiency (Glass, 2010).

Two of the most studied mTORC1 targets are the eukaryotic initiation factor $4 \mathrm{E}$ binding protein (4E-BP) 1 and p70S6K, which both play important roles in the initiation of mRNA translation. mTOR phosphorylates and activates the $70-\mathrm{kDa}$ ribosomal protein S6 kinase (p70S6K), which results in increased translation either directly or indirectly by activating initiation and elongation, elongation initiation factor (eIF)-2, eIF4E (through 4E-BP), and eEF-2 (Glass, 2010). In addition, Akt also phosphorylates and inactivates GSK-3 $\beta$, thereby activating translation via the initiation factor eIF2B. Other functions of Akt include the negative regulation of protein degradation by inhibiting FOXO-mediated proteasome activity.

Demontis and Perrimon (2009) showed that insulin receptor signaling and FOXO can regulate skeletal muscle atrophy also in Drosophila larval muscle. This study shows evolutionarily conservation of the mechanisms controlling muscle atrophy. It also shows a role for the transcription factors Myc and Mnt in this process (these are new factors that were not known to be involved in this process in mice or humans). Therefore, it is probable for the existence of novel signaling pathway via FOXO to regulate muscle hypertrophy and/or atrophy in mammals.

\section{ADAPTATION OF PI3-K/Akt/mTOR PATHWAY IN AGED MUSCLE}

Although many researchers consider PI3-K/Akt/mTOR levels to decrease with age, studies using sarcopenic muscles from rats and humans have yielded conflicting results. For example, compared with those in young Fischer $344 \times$ Brown Norway rats, the amounts of phosphorylated mTOR and p70S6K were increased $70-75 \%$ in the tibialis anterior (TA) but not in the plantaris muscle of senescent rats (Parkington et al., 2004). Kimball et al. (2004) showed that, in gastrocnemius muscle, the level of phosphorylated p70S6K, eIF2B activity, and the amount of eIF4E associated with eIF4G increased between 12 and 27 months of age despite an apparent decrease in Akt activity. In addition, other groups (Haddad and Adams, 2006; Léger et al., 2008) also showed the decreased phosphorylation status of Akt in aged mammalian muscle. In contrast, Rahnert et al. (2011) showed only significant 
decrease of phospho-p70S6K $\left(\mathrm{T}^{421} / \mathrm{S}^{424}\right)$ in the aged biceps brachii and no change in phospho-p70S6K $\left(\mathrm{T}^{389}\right)$, in spite of significant age-related decrease in p70S6K in all head and neck, tongue, and limb muscles (pectoralis, styloglossus, geniohyoid, posterior digastric, and masseter). Therefore, aging did not commonly modulate the PI3-K/Akt/mTOR-linked molecules in skeletal muscle under sedentary conditions.

Sarcopenic muscle shows a marked defect in the contractioninduced activation of these mediators. Parkington et al. (2004) reported lower levels of phosphorylated p70S6K and mTOR after high-frequency electrical stimulation [HFES, 3-s trains of pulses (frequency $100 \mathrm{~Hz}$, duration $1 \mathrm{~ms}$ at 10-12 V)] in muscle of senescent rats (30 months of age) compared with those in young rats (6 months of age). The same roup (Funai et al., 2006) also demonstrated that 4E-BP1 was markedly phosphorylated in the TA muscle of aged but not young rats at $6 \mathrm{~h}$ after HFES. In addition, they suggested no increase in eIF4E-eIF4G association after HFES in aged muscle (Funai et al., 2006). Furthermore, Thomson and Gordon (2006) suggested impaired overload-induced muscle growth in old rats possibly due to diminished phosphorylation of mTOR $\left(\right.$ Ser $\left.^{2448}\right)$, p70S6K (mTOR-specific Thr $\left.{ }^{389}\right)$, rpS6 $\left(\right.$ Ser $\left.^{235 / 236}\right)$, and $4 \mathrm{E}-\mathrm{BP} 1$. Fry et al. (2011) demonstrated that acute resistance exercise ( 8 sets of 10 repetitions of leg-extension at 70\% 1RM with 3 min of rest between each set) increased muscle-protein synthesis rate, and phosphorylation of mTOR, S6K1, and 4E-BP1 only in younger subjects ( $27 \pm 2$ years old) but not in elderly ones ( $70 \pm 2$ years old). These lines of evidence clearly show that sarcopenic muscle exhibits an impairment of Akt/mTOR/p70S6K signaling after contraction. This defect would explain the limited capacity for hypertrophy after muscle stimulation in aged animals.

\section{ADAPTATION OF THE PI3-K/AKt/mTOR PATHWAY IN DYSTROPHIC MUSCLE}

Functional deficiency of mTOR-dependent signaling is implicated in muscular dystrophy. Indeed, muscles lacking raptor (mTORC1 component) but not rictor (mTORC2 component) become progressively dystrophic and kyphotic, resulting in early death (Bentzinger et al., 2008). In the soleus and to a lesser extent in the EDL, raptor-deficient mice exhibited a wide distribution of fiber size, muscle fibers with centralized nuclei, and structures reminiscent of central cores (Bentzinger et al., 2008). Dystrophic muscle seems to exhibit induction of this anabolic pathway. Compared with age-matched wild-type mice, marked increases in pAkt/Akt, pS6/S6, and p4E-BP1/4E-BP1 were recognized in TA and diaphragm muscles of 4-month-old mdx mice (De Palma et al., 2012). Intriguingly, starvation was shown to elicit significant decreases in these anabolic mediators of mTOR-dependent signaling in both muscles of wild-type mice, but not those of mdx mice. Such hyperactivation of this signal markedly blocks autophagydependent signaling in both normal and starved mdx mice (De Palma et al., 2012). Age-related reductions of pAkt and pS6 levels occur in mdx mouse muscle. Indeed, Mouisel et al. (2010) showed marked decreases in pAkt (50\%) and pS6 (45\%) in mdx muscle at 18-24 months old compared with those at 5 months old. Intriguingly, the stimulation of muscle regeneration by cardiotoxin injury induces abnormal hyperactivation of pAkt and pS6. Therefore, sarcopenia muscle of mdx mice exhibits an apparent deficiency of PI3-K/Akt/mTOR signaling. However, as mdx mice age normally, caution is required when translating observations from mdx mice to human DMD patients. In addition, they similarly observed hyperactivation of pAkt and p4E-BP1, no induction of LC3-II, and accumulation of p62 in muscles of DMD patients. At 6 weeks of age, there was a significantly lower level of mTOR activation in diaphragm muscles of $\mathrm{mdx}$ mice compared with that of age-matched wild-type mice (Eghtesad et al., 2011). mTOR activation increased with postnatal age in diaphragm muscle of wild-type mice, but not in mdx mice. In contrast to diaphragm muscle, mTOR activation was not significantly different in the TA muscle of $\mathrm{mdx}$ and wild-type mice at either 6 or 12 weeks of age (Eghtesad et al., 2011). As contradicting results relating to the adaptive changes in PI3-K/Akt/mTOR in muscular dystrophy have been observed, future studies using human patients with muscular dystrophy are required. Strangely, a low-protein diet (De Palma et al., 2012) and treatment with rapamycin (Eghtesad et al., 2011) attenuate this anabolic pathway, but Wnt7a (von Maltzahn et al., 2012) and valproic acid (Gurpur et al., 2009) activate it. However, such therapeutics with overall different directions for mTOR-dependent signaling effectively attenuates the muscular dystrophic phenotype (muscle inflammation such as T-cell infiltration, fibrosis, myofiber damage, and the decrease of muscle strength).

\section{SERUM RESPONSE FACTOR}

Serum response factor is a ubiquitously expressed member of the MADS (MCM1, Agamous, Deficiens, and SRF) box transcription factor family, sharing a highly conserved DNAbinding/dimerization domain, which binds the core sequence of SRF/CArG boxes [CC (A/T)6 GG] as homodimers. SRFdependent signaling plays a major role in a variety of physiological processes, including cell growth, migration, and cytoskeletal organization (Pipes et al., 2006). Previous results obtained with specific SRF-knockout models by the Cre-LoxP system emphasize a crucial role for SRF in postnatal skeletal muscle growth and regeneration by modulating interleukin-4 and IGF-I (insulinlike growth factor-I) mRNA expression (Charvet et al., 2006). More recently, Mokalled et al. (2012) demonstrated that members of the myocardin family of transcriptional coactivators, MASTR, and myocardin-related transcription factor (MRTF)-A, are up-regulated in satellite cells in response to skeletal muscle injury. In addition, double-knockout satellite cells (MASTR and MRTF-A) impair skeletal muscle regeneration, probably due to the down-regulation of several modulators of cell cycle arrest (retinoblastoma, etc.). As proposed by Mokalled et al. (2012), the promoting role on muscle regeneration seems to be attributable to both MASTR/MEF2 and/or MRTF-A/SRF complexes because the mouse MASTR protein lacks SRF-interaction regions.

Serum response factor also enhances the hypertrophic process in muscle fibers after mechanical overloading (Gordon et al., 2001; Sakuma et al., 2003; Sakuma and Yamaguchi, 2012a, 2013a) as well as muscle differentiation and MyoD gene expression in vitro (Gauthier-Rouviére et al., 1996). Although SRF would regulate proliferation and differentiation using different pathways, it would mainly activate the differentiation of satellite cells during muscle hypertrophy. Indeed, we showed that, in mechanically overloaded 
muscles of rats, the SRF protein co-localized with MyoD and myogenin in myoblast-like cells during the active differentiation phase (Sakuma et al., 2003). More recently, Guerci et al. (2012) investigated the functional role of SRF in fiber hypertrophy using SRF $^{\text {flox/flox:HAS-Cre-ER }}{ }^{\mathrm{T} 2}$ mice injected with tamoxifen. Guerci et al. (2012) showed that the selective lack of SRF in myofibers markedly slows fiber growth after mechanical overloading by modulating satellite cell proliferation and fusion to the growing fibers. They demonstrated that, in the overloaded muscle, SRF enhances the expression of COX2 mRNA, which in turn upregulates IL-4 mRNA and ultimately secretes IL-4 protein. Guerci's hypothesis indicated that IL-4 produced by muscle fibers moves into satellite cells paracrinally to modulate the fusion of satellite cells.

It is proposed that the transcriptional activity of SRF is regulated by muscle ring finger (MuRF)-2 (Lange et al., 2005) and striated muscle activators of Rho signaling (STARS) (Kuwahara et al., 2005). At the M-band, the mechanically modulated kinase domain of titin interacts with a complex of the protein products of the atrogenes NBR1, p62/SQSTM-1, and MuRFs (Lange et al., 2005; Puchner et al., 2008). This complex dissociates under mechanical arrest, and MuRF-1 and MuRF-2 translocate to the cytoplasm and the nucleus (Lange et al., 2005; Ochala et al., 2011). One of the probable nuclear targets of MuRFs is SRF (Lange et al., 2005), suggesting that the MuRF-induced nuclear export and transcriptional repression of SRF may contribute to amplifying the transcriptional atrophy program (Spencer et al., 2000). Thus, it is possible that the synergistic transactivation of SRF and SRF-linked molecules is abrogated by MuRF-2 in vivo. On the other hand, SRF activity is exquisitely sensitive to the state of actin polymerization. G-actin monomers inhibit SRF activity, whereas polymerization of actin occurs in response to serum stimulation and RhoA signaling. In this pathway, signal inputs lower the ratio of globular actin to fibrillar actin, thereby liberating the binding of MRTF-A to globular actin, resulting in the nuclear accumulation of MRTFA and subsequent SRF-dependent gene expression (Miralles et al., 2003). It has been well established that overexpression of STARS contributes to the nuclear translocation of MRTF-A and MRTFB (Kuwahara et al., 2005, 2007), and these factors activate SRF transcription.

\section{ADAPTIVE CHANGES IN SRF-LINKED MOLECULES WITH AGE}

Mechanical loading for skeletal muscle is widely accepted to determine SRF expression. In humans, Lamon et al. (2009) demonstrated that 8 weeks of resistance training (leg presses, squats, and leg-extensions) induced increases in SRF mRNA (3-fold) and nuclear protein (1.25-fold) in the vastus lateralis muscle. In the same training period, they also observed a similar increase in the mRNA levels of several SRF-targeted molecules (alpha-actin, myosin heavy chain IIa, and IGF-I) (Charvet et al., 2006). Using RT-PCR, crude and fractionated homogenates, and immunofluorescence, our study demonstrated blunted expression of SRF protein in the quadriceps and triceps brachii muscles in aged mice (Sakuma et al., 2008). Immunofluorescence microscopy also indicated the selective down-regulation of SRF immunoreactivity in the cell cytosol but not in Pax7-labeled satellite cells in sarcopenic mice. In addition, our data showed a decrease in MRTF-A mRNA $(50-70 \%)$ and protein (76\%) levels in only the nuclear fraction with age. Furthermore, 60 and 40\% decreases in the amount of STARS mRNA were observed in the quadriceps and triceps brachii of 24-month-old mice, respectively (Sakuma et al., 2008). Intriguingly, a decrease of SRF expression achieved by a transgenic approach using the Cre-LoxP system was found to accelerate the atrophic process in muscle fibers with age (Lahoute et al., 2008). These SRF KO mice showed marked deposition of intramuscular lipids with aging. One morphologic aspect of sarcopenia is the infiltration of muscle tissue components by lipids because of the increased frequency of adipocyte or lipid deposition (Dubé and Goodpaster, 2006) within muscle fibers. As with precursor cells in bone marrow, liver, and kidney, muscle satellite cells expressing the adipocytic phenotype increased with age (Shefer et al., 2006), although this process is still relatively poorly understood in terms of its extent and spatial distribution. Lipid deposition, often referred to as intramuscular lipid deposition, may result from a net buildup of lipids due to the reduced oxidative capacity of muscle fibers with aging (Dubé and Goodpaster, 2006). These lines of evidence clearly show the existence of a defect of SRF signaling in aged mammalian muscle.

\section{ADAPTIVE CHANGES IN SRF-LINKED MOLECULES WITH MUSCULAR DYSTROPHY}

Serum response factor appears to be linked to the degenerative process during muscular dystrophy. Significant reductions in the amount of SRF have been observed (Sakuma et al., 2004), namely, $40-50$ and $50-65 \%$ at 2 and 12 weeks of age, respectively, in merosin-deficient congenital muscular dystrophy. Our immunohistochemical analysis indicated that mature normal mice had an abundance of SRF protein in the cytoplasm of several muscle fibers, while the dy mice did not. In the skeletal muscle, there is no direct evidence of a link between SRF disorders and the pathogenesis of disease. However, Lange et al. (2005) observed that a mutation in the TK domain of titin, a possible upstream modulator of SRF, disrupted Nbr1 binding, and led to hereditary myopathy with early respiratory failure (HMERF). HMERF patient biopsies revealed diffusible localization of $\mathrm{Nbr} 1$, large cytoplasmic aggregates of p62, and the selective accumulation of MuRF-2 in centralized nuclei in diseased muscle. Unfortunately, their study did not examine the localization of SRF in the muscle of HMERF patients. In contrast, human heart failure was reported to show elevations of a natural dominant-negative form of SRF arising from alternative splicing (Davis et al., 2002). The dominant-negative SRF isoform potently inhibited SRF-dependent gene expression, mirroring the biochemical phenotype seen in SRF-null mice (Davis et al., 2002). In addition, a subsequent human heart failure study showed decreases in full-length SRF and elevated expression of a caspase-3-cleaved product of SRF (Chang et al., 2003). A more recent review (Miano, 2010) proposed various disorders to be linked with the SRF mutations as shown by many reliable studies using cell-specific SRF-knockout phenotypes.

\section{UBIQUITIN-PROTEASOME SYSTEM}

The ATP-dependent UPS is essential for regulating protein degradation. The degradation of a protein via the UPS involves two steps: (1) tagging of the substrate by covalent attachment of multiple ubiquitin molecules and (2) degradation of the tagged 
protein by the $26 \mathrm{~S}$ proteasome complex with the release of a free and reusable ubiquitin. Ubiquitin, composed of 76 amino acids, is an $8.45-\mathrm{kDa}$ protein that is highly conserved in nearly all eukaryotes. The ubiquitination of proteins is regulated by at least three enzymes: ubiquitin-activating enzyme (E1); ubiquitinconjugating enzyme (E2); and ubiquitin ligase (E3). Kwak et al. (2004) suggested that the $14-\mathrm{kDa}$ ubiquitin-conjugating enzyme E2 $14 \mathrm{~K}$ and the ubiquitin ligase E3 are particularly important for the degradation of muscle-proteins. The labeled proteins are then fed into the cells' "waste disposers," the proteasomes, where they are chopped into small pieces and destroyed.

Atrogin-1 is a member of the Skp1, Cullin 1, and F-boxcontaining protein (SCF) complex, which bind together to establish E3 Ub-protein ligase activity, and features an approximately 40-amino-acid motif known as an F-box. MuRF-1 contains a canonical N-terminal RING domain characteristic of RINGcontaining E3 ligases followed by a MuRF family conserved region, zinc-finger domain (B-box), and leucine-rich coiled-coil domains. Consistent increases in atrogin-1 and MuRF-1 gene expression have been observed in a wide range of in vivo models of skeletal muscle atrophy including diabetes, cancer, renal failure, denervation, unweighting, and glucocorticoid or cytokine treatment (Bodine et al., 2001a; Lecker et al., 2004). The importance of these atrophy-regulated genes in muscle wasting was confirmed through knockout studies in mice where an absence of atrogin-1 or MuRF1 attenuated denervation-, fasting-, and dexamethasone-induced muscle atrophy (Bodine et al., 2001a; Baehr et al., 2011; Cong et al., 2011).

Yeast two-hybrid analysis identified eIF3 subunit 5 (eIF3-f) and MyoD as interactors of atrogin-1 (Lagirand-Cantaloube et al., 2008, 2009). Conversely, the knockdown of atrogin-1 reversed endogenous MyoD proteolysis and the overexpression of a mutant MyoD, unable to be ubiquitinated, prevented muscle atrophy in vivo (Lagirand-Cantaloube et al., 2009). These results confirmed MyoD as a substrate of atrogin-1, resulting in its polyubiquitination and subsequent degradation during dexamethasone-induced myotube atrophy (Jogo et al., 2009). In the heart, atrogin-1 ubiquitinates and reduces the levels of calcineurin A, an important factor triggering cardiac hypertrophy in response to pressure overload (Li et al., 2004). Interestingly, immunoprecipitation experiments in $\mathrm{C} 2 \mathrm{C} 12$ myoblasts and myotubes have found that atrogin-1 interacts with sarcomeric proteins, including myosins, desmin, and vimentin, as well as transcription factors, components of the translational machinery, enzymes involved in glycolysis and gluconeogenesis, and mitochondrial proteins (Lokireddy et al., 2012). Whether atrogin-1 ubiquitinates these proteins has yet to be proven. In contrast to atrogin-1, it appears that MuRF-1 mainly interacts with structural proteins. MuRF-1 was reported to interact with and control the half-life of many important muscle structural proteins, including troponin I, titin, myosin heavy chain (Clarke et al., 2007), actin (Polge et al., 2011), myosin binding protein C, and myosin light chains 1 and 2 (Cohen et al., 2009). For example, MuRF-1 degrades myosin light chains 1 and 2 under denervation and fasting conditions (Cohen et al., 2009). These studies suggest that, while numerous stimuli can activate both atrogin-1 and MuRF-1, the downstream pathways affected may be separate for each protein.

\section{ADAPTATION OF UPS IN AGED MUSCLE}

Only very indirect measurements [small increases in levels of mRNA encoding some components of the UPS (Bossola et al., 2008; Combaret et al., 2009) or ubiquitin-conjugate accumulation] in old muscles of rodents or humans suggested modest activation of this pathway. Atrogin-1 and/or MuRF-1 mRNA levels in aged muscle are reportedly increased (Clavel et al., 2006) or unchanged (Welle et al., 2003; Whitman et al., 2005) in humans and rats, or decreased in rats (DeRuisseau et al., 2005; Edström et al., 2006). Even when the mRNA expression of these atrogenes increased in sarcopenic muscles, this was very limited (1.5- to 2.5-fold) compared with that in other catabolic conditions (10-fold).

Although various findings have been made regarding the mRNA levels of both ubiquitin ligases in aged mammalian muscle, the examination of protein levels in sarcopenic muscles did not support age-related increases in the mRNA of several ubiquitin ligases. For instance, Edström et al. (2006) indicated the marked up-regulation of phosphorylated Akt and FOXO4 in the gastrocnemius muscle of aged female rats, probably contributing to the down-regulation of atrogin-1 and MuRF-1 mRNA. This result is further supported by the more recent finding of Léger et al. (2008) who, using human subjects aged 70 years old, demonstrated decreases in nuclear FOXO1 and FOXO3a by 73 and $50 \%$, respectively, although they did not recognize significant age-dependent changes in the expression of atrogin-1 and MuRF-1 mRNA. The major peptidase activities of the proteasome (i.e., the chymotrypsin-like, trypsin-like, and caspase-like activities) were either reduced (as reported in other tissues) or unchanged with aging (Combaret et al., 2009; Sakuma and Yamaguchi, 2011a). In contrast, Altun et al. (2010) recently found that the hindlimb muscles of (30-month-old) rats contained two to threefold more 26S proteasomes than purified from muscles of aged rats, and adult (control) rats showed a similar capacity to degrade peptides, proteins, and a ubiquitinated substrate, but differed in the levels of proteasome-associated proteins (e.g., the deubiquitinating enzyme USP14). Although the activities of many other deubiquitinating enzymes were greatly enhanced in aged muscles, levels of polyubiquitinated proteins were higher than in the adult animals. Interestingly, recent findings indicate that atrogin-1-knockout mice are short-lived and experience higher loss of muscle mass during aging than control mice (Sandri et al., 2013), indicating that the activity of this E3 ubiquitin ligase is required to preserve muscle mass during aging in mice. Moreover, MuRF-1-null mice experience higher decay of muscle strength during aging than controls, although muscle mass is at least in part preserved in these mice (Hwee et al., 2014). As indicated by Sandri et al. (2013), chronic inhibition of these atrogenes should not be considered a therapeutic target to counteract sarcopenia because this does not prevent muscle loss but instead exacerbates weakness.

\section{ADAPTATION OF UPS IN MUSCULAR DYSTROPHY}

Gene expression profiling in LGMD2A showed overexpression of UPS-related genes (Keira et al., 2007; Saenz et al., 2008). While the expression of atrogin-1 and MuRF-1 was not increased in mouse models of LGMD2A, FOXO1 was strongly up-regulated, and induced muscle atrophy in calpain-3-deficient mice (Laure 
et al., 2009). More recently, Fanin et al. (2013) demonstrated that LGMD2A patients exhibit significantly higher expression of MuRF-1 protein ( $146 \pm 64 \%$ of control) but not atrogin-1 protein ( $77 \pm 26 \%$ of control) in skeletal muscle.

LGMD2B is due to deficiency of the protein dysferlin, which causes failure in resealing of the membrane lesions generated during eccentric muscle contractions (Bansal et al., 2003). Similar to LGMD2A, dysferlinopathy patients exhibited more abundant mRNA and protein of MuRF-1 but not atrogin-1 (Fanin et al., 2014). Activation of UPS in dysferlinopathy has also been reported in cellular models (patient-derived muscle cells) (Azakir et al., 2012). Ullrich congenital muscular dystrophy (UCMD) is a common form of muscular dystrophy associated with defects in collagen VI. It is characterized by loss of individual muscle fibers and muscle mass and proliferation of connective and adipose tissues. More recently, Paco et al. (2012) studied muscle biopsies of UCMD $(n=6)$, other myopathy (DMD, calpain-3-deficient, Kearns-Sayre, and nemaline myopathy, $n=12$ ), and control patients $(n=10)$ and found reduced expression of atrogin- 1 and MuRF-1 mRNAs in UCMD cases.

In contrast to the case of sarcopenia, pharmacological inhibition of UPS appears to exert some beneficial effect on muscular dystrophy. Bonuccelli et al. (2007) indicated that Velcade, once injected locally into the gastrocnemius muscles of $\mathrm{mdx}$ mice, could upregulate the expression and membrane localization of dystrophin and members of the DAPC. Gazzerro et al. (2010) suggested that treatment with Velcade $(0.8 \mathrm{mg} / \mathrm{Kg})$ over a 2 -week period reduced muscle degeneration and necrotic features, and increased muscle size (gastrocnemius and diaphragm), in $\mathrm{mdx}$ muscle fibers. In addition, they observed many myotubes and/or immature myofibers expressing embryonic myosin heavy chain in mdx muscle after Velcade administration, probably due to upregulation of several myogenic differentiating modulators (MyoD and Myf-5). They also demonstrated that MG-132 increased dystrophin, $\alpha$-sarcoglycan, and $\beta$-dystroglycan levels in explants from BMD patients, whereas it increased levels of the DAPC in DMD cases.

\section{AUTOPHAGY-DEPENDENT SIGNALING}

Macroautophagy (herein autophagy) occurs in all eukaryotic cells and is evolutionarily conserved from yeast to humans. Autophagy is a ubiquitous catabolic process that involves the bulk degradation of cytoplasmic components through a lysosomal pathway (Sandri, 2010, 2011; Neel et al., 2013). This process is characterized by the engulfment of part of the cytoplasm inside double-membrane vesicles called autophagosomes. Autophagosomes subsequently fuse with lysosomes to form autophagolysosomes in which the cytoplasmic cargo is degraded and the degradation products are recycled for the synthesis of new molecules. Turnover of most long-lived proteins, macromolecules, biological membranes, and whole organelles, including mitochondria, ribosomes, the endoplasmic reticulum, and peroxisomes, is mediated by autophagy (Cuervo, 2004).

At first glance, autophagy was considered a coarse, nonselective, degradative system, but closer investigation revealed a different truth. Autophagy represents an extremely refined collector of altered organelles, abnormal protein aggregates, and pathogens, similar to a selective recycling center rather than a general landfill (Park and Cuervo, 2013). The selectivity of the autophagy process is conferred by a growing number of specific cargo receptors, including p62/SQSTM-1, Nbr1, Nix (Bnip3L), and optineurin (Shaid et al., 2013). These adaptor proteins are equipped with both a cargo-binding domain, with the capability to recognize and attach directly to molecular tags on organelles, and at the same time an LC3-interacting region domain, able to recruit and bind essential autophagosome membrane proteins.

De novo formation of autophagosomes is regulated by at least three molecular complexes: the LC3 conjugation system and the regulatory complexes governed by unc51-like kinase-1 (ULK1) and Beclin-1. The conjugation complex is composed of different proteins encoded by autophagy-related genes (Atg) (Mizushima and Komatsu, 2011). The Atg12-Atg5-Atg16L1 complex, along with Atg7, plays an essential role in the conjugation of LC3 to phosphatidylethanolamine, which is required for the elongation and closure of the isolation membrane (Mizushima and Komatsu, 2011). This system is under the regulation of at least two major cellular energy-sensing complexes. Under basal conditions, the ULK1 complex is inactivated by phosphorylation through mTORC1, whereas during autophagy induction mTORC1 is inhibited, thus enhancing the formation of a complex between ULK1, Atg13, and FIP200. In addition, mTORC1 can also be negatively regulated independently of Akt by energy stress sensors such as AMPK and, in a mechanical-activity-dependent manner, through TSC$1 / 2$. Moreover, AMPK can also directly phosphorylate ULK1 and Beclin-1 (Kim et al., 2013). During autophagy, the ULK1 complex is localized to the isolation membrane, where it facilitates the formation of autophagosomes through interaction with the Beclin-1 complex.

Interestingly, that the UPS and the lysosomal-autophagy system in skeletal muscle are interconnected was suggested by Mammucari et al. (2007), and Zhao et al. (2007). Both studies identified FOXO3 as a regulator of the lysosomal and proteasomal pathways in muscle wasting. FOXO3 is a transcriptional regulator of the ubiquitin ligases MuRF-1 and atrogin-1. It has now been linked to the expression of Atg in skeletal muscle in vivo and C2C12 myotubes (Zhao et al., 2007). More recently, Masiero et al. (2009) found an intriguing characteristic using muscle-specific autophagy-related gene (Atg7) knockout mice. The atrophy, weakness, and mitochondrial abnormalities in these mice are also features of sarcopenia.

\section{ADAPTATION OF AUTOPHAGY-LINKED SIGNALING IN MUSCLE WITH AGE}

A decline in autophagy during normal aging has been described for invertebrates and higher organisms (Cuervo et al., 2005). Inefficient autophagy has been attributed a major role in the apparent age-related accumulation of damaged mitochondria (Terman and Brunk, 2006).

Demontis and Perrimon (2010) showed that the function of autophagy/lysosome system of protein degradation declined during aging in the skeletal muscle of Drosophila. This results in the progressive accumulation of polyubiquitin protein aggregates in senescent Drosophila muscle. Intriguingly, overexpression of the FOXO increases the expression of many autophagy genes, 
preserves the function of the autophagy pathway, and prevents the accumulation of polyubiquitin protein aggregates in sarcopenic Drosophila muscle (Demontis and Perrimon, 2009). Several investigators reported the autophagic changes in aged mammalian skeletal muscle (McMullen et al., 2009; Wenz et al., 2009; Wohlgemuth et al., 2010; Gaugler et al., 2011). Compared with those in young male Fischer 344 rats, amounts of Beclin-1 were significantly increased in the plantaris muscles of senescent rats (Wohlgemuth et al., 2010). In contrast, aging did not influence the amounts of Atg7 and Atg9 proteins in rat plantaris muscle (Wohlgemuth et al., 2010). Indeed, Western blot analysis by Wohlgemuth et al. (2010) clearly showed a marked increase in the amount of LC3 in muscle during aging. However, they could not demonstrate an aging-related increase of the ratio of LC3-II to LC3-I, a better biochemical marker to assess ongoing autophagy. In contrast, Wenz et al. (2009) recognized a significant increase in the ratio of LC3-II to LC3-I during aging (3 vs. 22 months) in the biceps femoris muscle of wild-type mice. None of the studies determining the transcript level of autophagy-linked molecules found a significant increase with age (McMullen et al., 2009; Wohlgemuth et al., 2010; Gaugler et al., 2011). Not all contributors to autophagy signaling seem to change similarly at both mRNA and protein levels in senescent skeletal muscle. Therefore, sarcopenia may include a partial defect of autophagy signaling, although more exhaustive investigation is needed in this field.

Life-long caloric restriction alone, or combined with voluntary exercise, resulted in mild reduction of LC3 expression and lipidation coupled with increased LAMP-2 (lysosomal marker) expression, suggesting a potential increase in autophagy flux. No significant age-related increase in autophagy-linked molecules was observed in MCK-PGC- $1 \alpha$ mice. PGC- $1 \alpha$ may also enhance autophagic flux. More recently, GSK- $3 \alpha$ was proposed as a critical regulator of aging in various organs (skeletal muscle, heart, liver, bone, etc.) via modulating mTORC1 and autophagy. Intriguingly, mice with null mutation of GSK-3 $\alpha$ showed premature death and acceleration of age-related pathologies such as vacuolar degeneration, large tubular aggregates, sarcomere disruption, and striking sarcopenia in cardiac and skeletal muscle (Zhou et al., 2013). These GSK-3 $\alpha$ KO mice exhibited marked activation of mTORC1 and associated suppression of several autophagy molecules. Indeed, unrestrained activation of mTORC1 leads to profound inhibition of autophagy (Levine and Kroemer, 2008; Kroemer et al., 2010). Therefore, it is expected that pharmacological inhibition (everolimus) of mTORC1 rescued the muscular disorder resembling sarcopenia in GSK-3 $\alpha$ KO mice (Zhou et al., 2013). Enhancement of autophagy flux (exercise, caloric restriction, etc.) would be a potential strategy attenuating sarcopenia as well as various type of muscular dystrophy with autophagy defect (Grumati et al., 2010; De Palma et al., 2012; Vainshtein et al., 2014).

\section{ADAPTATION OF AUTOPHAGY-LINKED SIGNALING IN MUSCULAR DYSTROPHY}

A finely tuned system for protein degradation and organelle removal is required for the proper function and contractility of skeletal muscle (Vainshtein et al., 2014). Inhibition/alteration of autophagy contributes to myofiber degeneration leading to accumulation of abnormal (dysfunctional) organelles and of unfolded and aggregation-prone proteins (Masiero et al., 2009; Sandri, 2010), which are typical features of several myopathies (Grumati et al., 2010; Nogalska et al., 2010). Generation of Atg5 and Atg7 muscle-specific knockout mice confirmed the physiological importance of the autophagy system in muscle mass maintenance (Raben et al., 2008; Masiero et al., 2009). The muscle-specific Atg7 knockout mice are characterized by the presence of abnormal mitochondria, oxidative stress, accumulation of polyubiquitinated proteins, and consequent sarcomere disorganization (Masiero et al., 2009). In addition, the central role of the autophagylysosome system in muscle homeostasis is highlighted by lysosomal storage diseases (Pompe disease, Danon disease, and X-linked myopathy), a group of debilitating muscle disorders characterized by alterations in lysosomal proteins and autophagosome buildup (Vainshtein et al., 2014). Intriguingly, all of these myopathies exhibit the accumulation of autophagic vacuoles inside myofibers due to defects in their clearance.

Apparent defect of autophagy-dependent signaling is also observed in various muscular dystrophies. The first evidence of impaired autophagy in these models was provided by studies in mice and patients with mutations in collagen VI (Irwin et al., 2003). Mutations that inactivate Jumpy, a phosphatase that counteracts the activation of VPS34 for autophagosome formation and reduces autophagy, are associated with centronuclear myopathy (Vergne et al., 2009). De Palma et al. (2012) have described marked defect of autophagy in dystrophin-deficient mdx mice and DMD patients. This evidence included the electron microscopic evaluation of muscle tissue morphology as well as the decreased expression of autophagic regulator proteins (i.e., LC3-II, Atg12, Gabarapl1, and Bnip3). In addition, starvation and treatment with chloroquine, potent inducers of autophagy, did not activate autophagy-dependent signaling in both TA and diaphragm muscles of mdx mice (De Palma et al., 2012). Furthermore, mdx mice and DMD patients exhibited an unnecessary accumulation of p62 protein, which was lost after prolonged autophagy induction by a low-protein diet (De Palma et al., 2012). A similar block in autophagy progression was described in lamin $\mathrm{A} / \mathrm{C}$ null mice (Ramos et al., 2012). LGMD2A muscles showed up-regulation of p62 (2.1-fold) and Bnip3 (3-fold) mRNA and slightly increased LC3-II/LC3-I protein ratio and p62 (Fanin et al., 2013). Conversely, laminin-mutated (dy/dy) animals displayed excessive levels of autophagy, which is equally detrimental (Carmignac et al., 2011). These findings suggest that the defect of autophagy signaling has a central role in the degenerative symptoms in various types of muscular dystrophy. Figure 1 shows a schematic diagram of possible relationship between Akt-mTOR signaling and autophagy in muscular dystrophy.

\section{MYOSTATIN}

Growth and differentiation factor 8, otherwise known as myostatin, was first discovered during screening for novel members of the transforming growth factor- $\beta$ (TGF- $\beta$ ) superfamily, and shown to be a potent negative regulator of muscle growth (Lee, 2004). Like other TGF- $\beta$ family members, myostatin is synthesized as a precursor protein that is cleaved by furin proteases to generate the active $\mathrm{C}$-terminal dimer. When produced in Chinese hamster ovary cells, the C-terminal dimer remains bound to the 


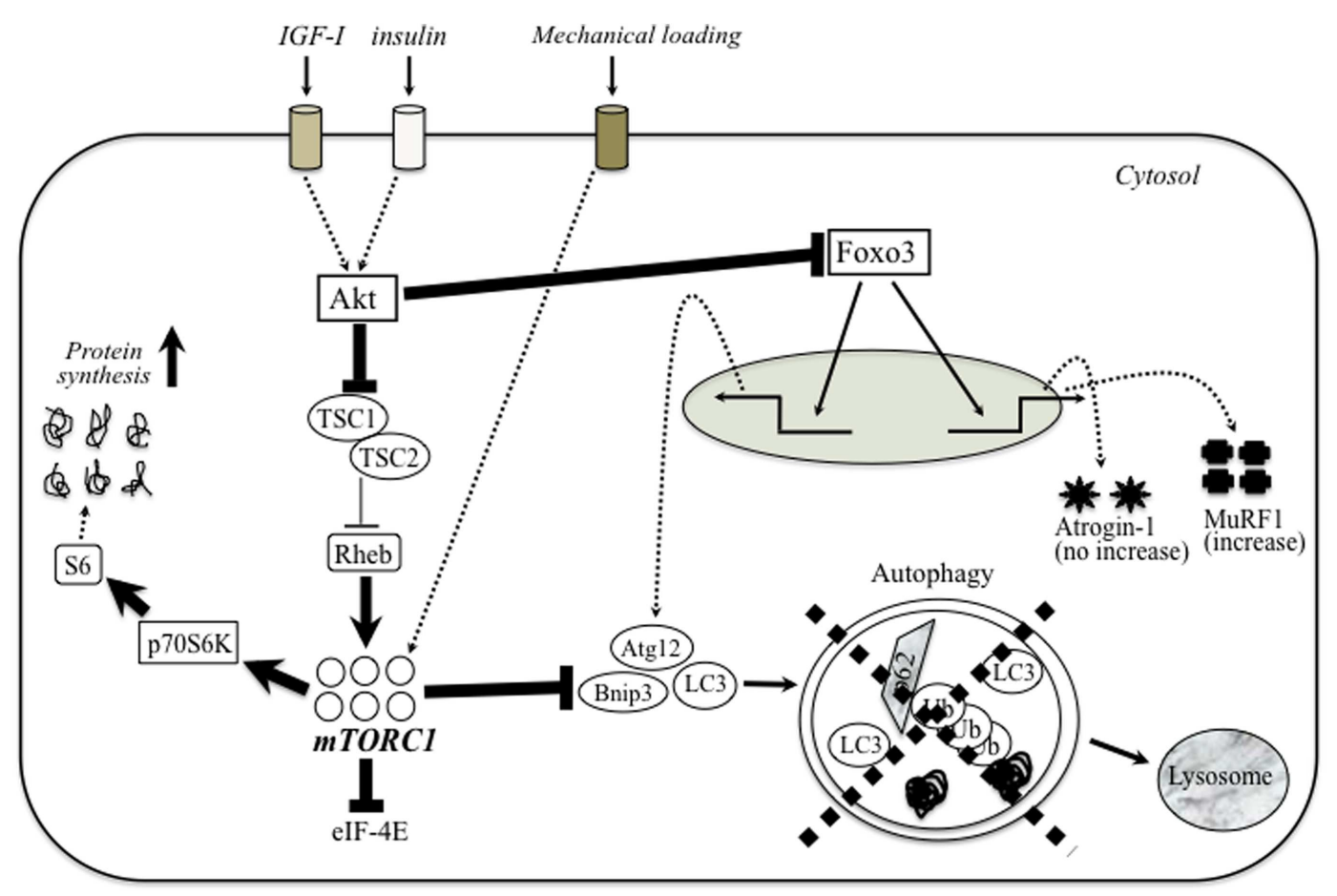

FIGURE 1 |The relationship between PI3-K-Akt-mTOR signaling and autophagy in muscular dystrophy. The major anabolic pathway regulating protein synthesis in skeletal muscle is $\mathrm{MTOR} / \mathrm{TORC} 1$ signaling. Upstream trigger (IGF-1, mechanical stress, etc.) activates mTOR signaling through a number of different intermediary proteins such as Akt and Rheb. Several anabolic stimulation increases the amount of activated Akt, which blocks the nuclear translocation of Foxo3 to enhance the expression of autophagy-related genes (Bnip, LC3, and Atg12) and atrogene (atrogin-1 and MuRF-1). In dystrophic muscle, higher Akt potently blocks the inhibition of Rheb by TSC-1/TSC-2, and hyperactivate mTORC1. Unnecessary activated mTORC1 would extremely enhance protein synthesis and blocks autophagy-dependent signaling. Therefore, muscular dystrophy exhibits apparent defect of autophagic process similar to sarcopenic muscle.
$\mathrm{N}$-terminal propeptide, which remains in a latent, inactive state (Wolfman et al., 2003). Most, if not all, of the myostatin protein that circulates in the blood also appears to exist in an inactive complex with a variety of proteins, including the propeptide. Myostatin binds to and signals through a combination of ActRIIA/B receptors on the cell membrane, but has higher affinity for activin type IIB receptor (ActRIIB). On binding to ActRIIB, myostatin forms a complex with a second surface type I receptor, either activin receptor-like kinase 4 or 5 , to stimulate the phosphorylation of Receptor Smad (R-Smad) and the Smad2/3 transcription factors in the cytoplasm. This leads to the assembly of Smad2/3 with Smad4 to form a heterodimer that can translocate to the nucleus and activate the transcription of target genes (Joulia-Ekaza and Cabello, 2007). Myostatin circulates in the blood in a latent complex with non-covalently bound propeptide at the $\mathrm{N}$-terminus (Wolfman et al., 2003).

Studies indicate that myostatin inhibits cell cycle progression and reduces the levels of myogenic regulatory factors, thereby controlling myoblastic proliferation and differentiation during developmental myogenesis (Yang et al., 2007). One of the known downstream targets of Smad signaling is MyoD. Interestingly, myostatin downregulates MyoD expression in an NF$\kappa \mathrm{B}$-independent way (McFarlane et al., 2006). Myostatin also inhibits Pax3 expression, which is possibly an upstream target of
MyoD (McFarlane et al., 2006). On the other hand, the genetic loss of myostatin leads to an increase in Akt activity in skeletal muscle in vivo and in vitro (Morissette et al., 2009). The IGF1-Akt-mTOR pathway, which mediates both differentiation in myoblasts and hypertrophy in myotubes, has been shown to inhibit myostatin-dependent signaling. Blockade of the Akt-mTOR pathway using siRNA to RAPTOR, a component of TOR signaling complex 1 (TORC1), facilitates myostatin's inhibition of muscle differentiation because of an increase in Smad2 phosphorylation (Trendelenburg et al., 2009). Taking these findings, myostatinmediated signaling activates FOXO, which leads to the expression of ubiquitin ligases.

\section{ADAPTIVE CHANGES IN MYOSTATIN IN SARCOPENIC MUSCLE}

Myostatin levels increase with muscle atrophy due to unloading in mice and humans (Wehling et al., 2000; Sakuma et al., 2009), and with severe muscle wasting in patients with cancer cachexia, chronic heart failure, chronic obstructive pulmonary disease (COPD), AIDS, and diabetes (Sakuma and Yamaguchi, 2011b). Many researchers have investigated the effect of inhibiting myostatin to counteract sarcopenia using animals (Siriett et al., 2006; LeBrasseur et al., 2009; Murphy et al., 2010). LeBrasseur et al. (2009) reported several positive effects of 4 weeks of treatment with PF-354 $(24 \mathrm{mg} / \mathrm{Kg})$ in aged mice. They found that 
PF-354-treated mice exhibited significantly greater muscle mass (by $12 \%$ ) probably due to decreased levels of phosphorylated Smad3 and MuRF-1 in muscle. More recently, Murphy et al. (2010) showed, by way of once-weekly injections, that a lower dose of PF$354(10 \mathrm{mg} / \mathrm{Kg})$ significantly increased the fiber cross-sectional area (by 12\%) and in situ muscle force (by 35\%) of aged mice (21-month-old).

However, the role of myostatin in driving sarcopenia is debated. There is indeed evidence that myostatin null mice, although they have a doubling of muscle mass, have reduced specific force and may be actually prone to sarcopenia, suggesting that the intrinsic capacity to generate force is perturbed in the absence of myostatin (Amthor et al., 2007; Gentry et al., 2011). In addition, a recent study in Drosophila on the myostatin/GDF11 homolog myoglianin indicates that, in the absence of changes in muscle mass, overexpression of myoglianin (Drosophila myostatin) in muscle extends lifespan and preserves muscle function at least in part by activating the stress-sensing kinase p38 MAPK, while myoglianin RNAi in muscle has converse effects (Demontis et al., 2014; Patel and Demontis, 2014).

In rodent muscle models, studies using sarcopenic muscles have yielded conflicting results (Haddad and Adams, 2006; Carlson et al., 2008; Bowser et al., 2013). Haddad and Adams (2006) showed lower expression of myostatin mRNA in aged (30-monthold) than in young (6-month-old) rats. Carlson et al. (2008) showed higher levels of TGF- $\beta$ and Smad3 but not myostatin in sarcopenic muscles of mice. In humans, an early cross-sectional study of younger, middle-aged, and older men and women suggested that serum myostatin levels increase with advancing age, are highest in "physically frail" older women, and are inversely associated with skeletal muscle mass (Yarasheski et al., 2002). However, several subsequent reports on humans failed to show age-related differences in either circulating myostatin-immunoreactive protein or skeletal muscle myostatin mRNA levels (Welle et al., 2003; Ratkevicius et al., 2011). In contrast, Léger et al. (2008) found a significant elevation in myostatin mRNA and protein levels by 2 - and 1.4-fold in young ( $20 \pm 0.2$ years) males compared with those in older ( $70 \pm 0.3$ years $)$ ones. These disparate findings suggest that myostatin may not be a primary driver of sarcopenia, or may instead highlight the complexities related to myostatin and its measurements. As indicated by a recent review (White and LeBrasseur, 2014), three possible reasons for this exist. First, myostatin abundance may not reflect myostatin activity. Indeed, myostatin is generated as a precursor protein that requires proteolytic cleavage first to remove its signal peptide and then to liberate an $\mathrm{N}$-terminal propeptide and a C-terminal fragment. The mature biologically active form of myostatin is only a disulfide-linked dimer of C-terminal fragments. Second, myostatin is further regulated by at least three interacting proteins, namely, GDF-associated serum protein-1 (GASP-1), follistatin, and follistatin-related gene (FLRG) (Lee, 2004). It is plausible that the abundance of these endogenous inhibitors of myostatin and/or the degree to which they interact with myostatin is independently affected by aging. Third, we may not detect the expression pattern of myostatin during sarcopenia because of very small changes of this molecule at only a limited position of an organelle (e.g., satellite cells), but not throughout muscle fibers. Indeed, a recent study revealed that muscle-derived stem cells from older male patients show a $+65 \%$ higher level of myostatin expression than stem cells from younger patients (McKay et al., 2012). Although myostatin immunoreactivity on satellite cells gradually decreased the response to acute resistance exercise, old muscles possessed more abundant myostatin on satellite cells of type II fibers than young muscles postexercise. More descriptive study to investigate a detailed cellular localization of myostatin would detect such a limited but important adaptation of myostatin in sarcopenic muscle.

\section{FUNCTIONAL ROLE OF MYOSTATIN IN DYSTROPHIC MUSCLE}

There have been several studies dealing with the adaptive changes in myostatin expression of muscular dystrophy. Using muscles from fetopsies, infants (aged 8-10 months), and symptomatic patients (aged 5-12 years) with DMD, Chen et al. (2005) performed mRNA profiling. They demonstrated no induction of myostatin mRNA at any stage of the disease determined in their study. Similarly, no induction of myostatin was also observed in DMD muscle by Castro-Gago et al. (2006). Zanotti et al. (2007) showed significant increases in myostatin transcript and protein levels in DMD myotube cultures in vitro. In contrast, a screen of 12,488 mRNAs in 16-week-old mouse mdx muscle showed a marked decrease (fourfold) in myostatin mRNA (Tseng et al., 2002). Similar down-regulation of myostatin mRNA was observed in mdx mice using suppression subtractive hybridization (Tkatchenko et al., 2000). Therefore, myostatin does not seem to modulate the atrophy and degeneration of skeletal muscle in DMD and mdx mice, since common adaptation of myostatin levels did not occur in these dystrophic muscles.

Many mutations in the caveolin-3 gene have been detected in autosomal dominant LGMD1C and autosomal dominant rippling muscle disease (AD-RMD) (Minetti et al., 1998; Betz et al., 2001). Immunoprecipitation and subsequent immunoblot analysis revealed that caveolin-3 associates with the type I myostatin receptor in COS-7 monkey kidney cells in vitro (Ohsawa et al., 2008). Intriguingly, caveolin-3 seems to suppress myostatin signaling by blocking the type I myostatin receptor. Therefore, caveolin3-deficient mice showed hyperphosphorylation of an R-Smad of myostatin, Smad2, and significant up-regulation of a myostatin target gene, p21 (Ohsawa et al., 2006). In addition, severe muscle histopathology was occasionally observed in the proximal muscles of patients with LGMD2I, whereas distal muscles were always relatively spared. In these patients, the amount of myostatin protein was highly increased in severely affected muscles compared with that in mildly affected ones. Hauerslev et al. (2013) hypothesize that alterations in the protein turnover and myostatin levels could progressively impair the muscle mass maintenance and/or regeneration, resulting in gradual muscular atrophy in LGMD2I. However, comprehensive analysis using a larger sample size of LGMD2I patients is needed as the hypothesis was generated from a very small sample size (severe phenotype $n=1$; mild phenotype $n=3$ ). In contrast, our previous study found a marked increase in mature myostatin protein $(26 \mathrm{kDa})$ in gastrocnemius and rectus femoris muscles of merosin-deficient congenital dy mice at 12 weeks of age (Sakuma et al., 2004). In addition, marked myostatin immunoreactivity was detected in the cytoplasm of myonuclei and/or satellite cells of dy mice compared with slight 

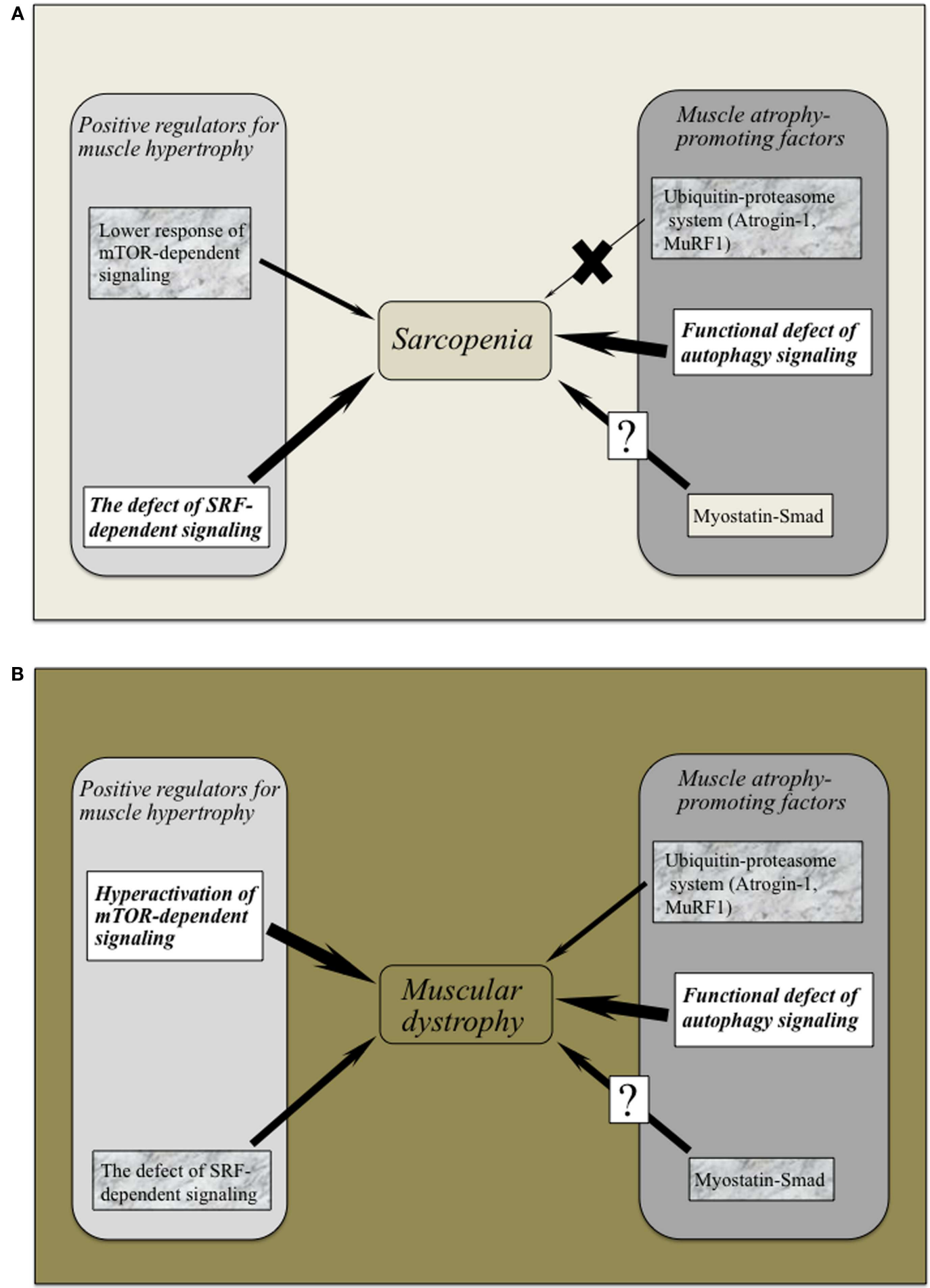

FIGURE 2 | (A,B) The adaptative changes of positive and negative regulators for muscle mass in sarcopenia and muscular dystrophy. Both sarcopenia and muscular dystrophy exhibit the marked defect of autophagy-dependent signaling possibly the latter due to hyperactivation of $\mathrm{Akt} / \mathrm{mTOR} / \mathrm{p} 70 \mathrm{S6K}$ pathway. Lower activation of SRF-dependent signaling has been commonly recognized in these symptoms. Ubiquitin-proteasome system (Atrogin-1 and MuRF-1) would not regulate muscle atrophy in the case of sarcopenia. It remains to be elucidated whether myostatin-Smad pathway regulates to sarcopenic symptom and/or muscular dystrophy. 
myostatin immunoreactivity at those sites in normal mice. Therefore, muscular dystrophy except for dystrophin deficiency induces the enhancement of myostatin-dependent signaling.

Many therapeutic approaches using myostatin attenuation have been conducted in muscular dystrophy. The use of neutralizing antibodies to myostatin improved muscle disorders in rodent models of DMD (mdx) and limb-girdle muscular dystrophy $2 \mathrm{f}$ (Sgcg-/-) (Bogdanovich et al., 2002; Bradley et al., 2008). Targeting of the $\mathrm{C}$-terminal dimer by a neutralizing monoclonal antibody (JA16) resulted in increases in muscle mass and function in wild-type mice (Whittemore et al., 2003) and rescued the pathological phenotype in dystrophin-deficient mdx mice (Bogdanovich et al., 2002). The latter study was the first to provide evidence that blocking myostatin in dystrophic mice increased myofiber size and alleviated the symptoms of the disease, such as a decline in strength, the degeneration of fibers, and fibrosis. The inhibition of myostatin was also effective in alleviating the pathological phenotype of caveolin-3-deficient mice (a model of LGMD1C) (Ohsawa et al., 2006). In contrast, myostatin blockade did not attenuate the pathology in a mouse model of merosin-deficient muscular dystrophy.

Intriguingly, myostatin inhibition using MYO-029 (Stamulumab) was tested in a prospective, randomized, placebocontrolled US phase I/II trial in 116 adults with muscular dystrophy such as BMD, fascioscapulohumeral muscular dystrophy (FSHD), and LGMD (Wagner et al., 2008). MYO-029 has good safety and tolerability except for cutaneous hypersensitivity at higher doses ( 10 and $30 \mathrm{mg} / \mathrm{Kg}$ ), attributed to the need for repeated protein administration (Wagner et al., 2008). No improvements in muscle function were noted, but dual-energy radiographic absorptiometry and muscle histological investigations revealed that some subjects had increased muscle fiber size. The trial study concluded that the systemic administration of myostatin inhibitors was relatively safe and that more potent inhibitors for stimulating muscle growth in muscular dystrophy should be considered. However, careful attention should be paid to myostatin inhibition, as mice with null mutation of myostatin revealed impaired tendon structure and function (Mendias et al., 2008). Figures 2A,B provide an overview of the positive and negative regulator adaptations of muscle mass in sarcopenia and muscular dystrophy.

\section{CONCLUSION}

In conclusion, both sarcopenia and muscular dystrophy exhibit the marked defect of autophagy-dependent signaling possibly the latter due to hyperactivation of Akt/mTOR/p70S6K pathway. Lower activation of SRF-dependent signaling has been commonly recognized in these symptoms. Although studies using rodent muscles have indicated that Atrogin-1 and MuRF contribute to the protein degradation in muscular wasting (Bodine et al., 2001a), these atrogenes do not regulate age-related muscle atrophy. More descriptive study seems to have detected such a limited but important adaptation of myostatin during sarcopenia.

\section{ACKNOWLEDGMENTS}

This work was supported by a research Grant-in-Aid for Scientific Research C (No. 23500778) from the Ministry of Education, Culture, Sports, Science, and Technology of Japan.

\section{REFERENCES}

Altun, M., Besche, H. C., Overkleeft, H. S., Piccirillo, R., Edelmann, M. J., Kessler, B. M., et al. (2010). Muscle wasting in aged, sarcopenic rats is associated with enhanced activity of the ubiquitin proteasome pathway. J. Biol. Chem. 285, 39597-39608. doi:10.1074/jbc.M110.129718

Amthor, H., Macharia, R., Navarrete, R., Schuelke, M., Brown, S. C., Otto, A. et al. (2007). Lack of myostatin results in excessive muscle growth but impaired force generation. Proc. Natl. Acad. Sci. U.S.A. 104, 1835-1840. doi:10.1073/pnas. 0604893104

Andersen, J. L. (2003). Muscle fiber type adaptation in the elderly human muscle. Scand. J. Med. Sci. Sports 13, 40-47. doi:10.1034/j.1600-0838.2003.00299.x

Azakir, B. A., Di Fulvio, S., Kinter, J., and Sinnreich, M. (2012). Proteasomal inhibition restores biological function of missense mutated dysferlin in patientderived muscle cells. J. Biol. Chem. 287, 10344-10354. doi:10.1074/jbc.M111. 329078

Baehr, L. M., Furlow, J. D., and Bodine, S. C. (2011). Muscle sparing in muscle RING finger 1 null mice: response to synthetic glucocorticoids. J. Physiol. 589, 4759-4776. doi:10.1113/jphysiol.2011.212845

Bansal, D., Miyake, K., Vogel, S. S., Groh, S., Chen, C. C., Williamson, R., et al. (2003). Defective membrane repair in dysferlin-deficient muscular dystrophy. Nature 423, 168-172. doi:10.1038/nature01573

Baumgartner, R. N., Waters, D. L., Gallagher, D., Morley, J. E., and Garry, P. J. (1999). Predictors of skeletal muscle mass in elderly men and women. Mech. Ageing Dev. 107, 123-136. doi:10.1016/S0047-6374(98)00130-4

Bentzinger, C. F., Romanino, K., Cloëtta, D., Lin, S., Mascarenhas, J. B., Oliveri, F., et al. (2008). Skeletal muscle-specific ablation of raptor, but not of rictor, causes metabolic changes and results in muscle dystrophy. Cell Metab. 8, 411-424. doi:10.1016/j.cmet.2008.10.002

Berger, M. J., and Doherty, T. J. (2010). Sarcopenia: prevalence, mechanisms, and functional consequences. Interdiscip. Top. Gerontol. 37, 94-114. doi:10.1159/ 000319997

Betz, R. C., Schoser, B. G., Kasper, D., Ricker, K., Ramírez, A., Stein, V., et al. (2001). Mutations in CAV3 causes mechanical hyperirritability of skeletal muscle in rippling muscle disease. Nat. Genet. 28, 218-219. doi:10.1038/90050

Bodine, S. C., Latres, E., Baumhueter, S., Lai, V. K., Nunez, L., Clarke, B. A., et al. (2001a). Identification of ubiquitin ligases required for skeletal muscle atrophy. Science 294, 1704-1708. doi:10.1126/science.1065874

Bodine, S. C., Stitt, T. N., Gonzalez, M., Kline, W. O., Stover, G. L., Bauerlein, R., et al. (2001b). Akt/mTOR pathway is a crucial regulator of skeletal muscle hypertrophy and can prevent muscle atrophy in vivo. Nat. Cell Biol. 3, 1014-1019. doi:10.1038/ncb1101-1014

Bogdanovich, S., Krag, T. O., Barton, E. R., Morris, L. D., Whittemore, L. A., Ahima, R. S., et al. (2002). Functional improvement of dystrophic muscle by myostatin blockade. Nature 420, 418-421. doi:10.1038/nature01154

Bonuccelli, G., Sotgia, F., Capozza, F., Gazzerro, E., Minetti, C., and Lisanti, M. P. (2007). Localized treatment with a novel FDA-approved proteasome inhibitor blocks the degradation of dystrophin and dystrophin-associated proteins in $\mathrm{mdx}$ mice. Cell Cycle 6, 1242-1248. doi:10.4161/cc.6.10.4182

Bossola, M., Pacelli, F., Costelli, P., Tortorelli, A., Rosa, F., and Doglietto, G. B. (2008). Proteasome activities in the rectus abdominis muscle of young and older individuals. Biogerontology 9, 261-268. doi:10.1007/s10522-008-9135-9

Bowser, M., Herberg, S., Arounleut, P., Shi, X., Fulzele, S., Hill, W. D., et al. (2013). Effects of the activin A-myostatin-follistatin system on aging bone and muscle progenitor cells. Exp. Gerontol. 48, 290-297. doi:10.1016/j.exger. 2012.11.004

Bradley, L., Yaworsky, P. J., and Walsh, F. S. (2008). Myostatin as a therapeutic target for musculoskeletal disease. Cell. Mol. Life Sci. 65, 2119-2124. doi:10.1007/ s00018-008-8077-3

Candow, D. G., and Chilibeck, P. D. (2005). Differences in size, strength, and power of upper and lower body muscle groups in young and older men. J. Gerontol. A Biol. Sci. Med. Sci. 60, 148-156. doi:10.1093/gerona/60.2.148

Cao, P. R., Kim, H. J., and Lecker, S. H. (2005). Ubiquitin-protein ligases in muscle wasting. Int. J. Biochem. Cell Biol. 37, 2088-2097. doi:10.1016/j.biocel.2004.11. 010

Carlson, M. E., Hsu, M., and Conboy, I. M. (2008). Imbalance between pSmad3 and Notch induces CDK inhibitors is old muscle stem cells. Nature 454, 528-532. doi:10.1038/nature07034

Carmignac, V., Svensson, M., Körner, Z., Elowsson, L., Matsumura, C., Gawlick, K. I., et al. (2011). Autophagy is increased in laminin $\alpha 2$ chain-deficient muscle and 
its inhibition improves muscle morphology in a mouse model of MDC1A. Hum. Mol. Genet. 20, 4891-4902. doi:10.1093/hmg/ddr427

Castro-Gago, M., Blanco-Barca, M. O., Eiris-Punal, J., Carneiro, I., Arve, V. M., and Devesa, J. (2006). Myostatin expression in muscular dystrophies and mitochondrial encephalomyopathies. Pediatr. Neurol. 34, 281-284. doi:10.1016/j. pediatrneurol.2005.08.009

Chang, J., Wei, L., Otani, T., Youker, K. A., Entman, M. L., and Schwartz, R. J. (2003). Inhibitory cardiac transcription factor, SRF-N, is generated by caspase 3 cleavage in human heart failure and attenuated by ventricular unloading. Circulation 108, 407-413. doi:10.1161/01.CIR.0000084502.02147.83

Charvet, C., Houbron, C., Parlakian, A., Giordani, J., Lahoute, C., Bertrand, A., et al. (2006). New role for serum response factor in postnatal skeletal muscle growth and regeneration via the interleukin 4 and insulin-like growth factor 1 pathways. Mol. Cell. Biol. 26, 6664-6674. doi:10.1128/MCB.00138-06

Chen, Y. W., Nagaraju, K., Bakay, M., McIntyre, O., Rawat, R., Shi, R., et al. (2005). Early onset of inflammation and later involvement of TGFbeta in Duchenne muscular dystrophy. Neurology 65, 826-834. doi:10.1212/01.wnl.0000173836. 09176.c4

Clarke, B. A., Drujan, D., Willis, M. S., Murphy, L. O., Corpina, R. A., Burova, E., et al. (2007). The E3 ligase MuRF1 degrades myosin heavy chain protein in dexamethasone-treated skeletal muscle. Cell Metab. 6, 376-385. doi:10.1016/j. cmet.2007.09.009

Clavel, S., Coldefy, A. S., Kurkdjian, E., Salles, J., Margaritis, I., and Derijard, B. (2006). Atrophy-related ubiquitin ligases, atrogin-1 and MuRF1 are upregulated in aged rat tibialis anterior muscle. Mech. Ageing Dev. 127, 794-801. doi:10.1016/j.mad.2006.07.005

Coffey, V. G., Zhong, Z., Shield, A., Canny, B. J., Chibalin, A. V., Zierath, J. R., et al. (2006). Early signaling responses to divergent exercise stimuli in skeletal muscle from well-trained humans. FASEB J. 20, 190-192. doi:10.1096/fj.054809fje

Cohen, S., Brault, J. J., Gygi, S. P., Glass, D. J., Valenzuela, D. M., Gartner, C., et al. (2009). During muscle atrophy, thick, but not thin, filament components are degraded by MuRF1-dependent ubiquitylation. J. Cell Biol. 185, 1083-1095. doi: $10.1083 /$ jcb.200901052

Combaret, L., Dardevet, D., Béchet, D., Taillandier, D., Mosoni, L., and Attaix, D. (2009). Skeletal muscle proteolysis in aging. Curr. Opin. Clin. Nutr. Metab. Care 12, 37-41. doi:10.1097/MCO.0b013e32831b9c31

Cong, H., Sun, L., Liu, C., and Tien, P. (2011). Inhibition of atrogin-1/MAFbx expression by adenovirus-delivered small hairpin RNAs attenuates muscle atrophy in fasting mice. Hum. Gene Ther. 22, 313-324. doi:10.1089/hum.2010.057

Cuervo, A. M. (2004). Autophagy: many paths to the same end. Mol. Cell. Biochem. 263, 55-72. doi:10.1023/B:MCBI.0000041848.57020.57

Cuervo, A. M., Bergamini, E., Brunk, U. T., Dröge, W., Ffrench, M., and Terman, A. (2005). Autophagy and aging: the importance of maintaining "clean" cells. Autophagy 1, 131-140. doi:10.4161/auto.1.3.2017

Davis, F. J., Gupta, M., Pogwizd, S. M., Bacha, E., Jeevanandam, V., and Gupta, M. P. (2002). Increased expression of alternatively spliced dominant-negative isoform of SRF in human failing hearts. Am. J. Physiol. Heart Circ. Physiol. 282, H1521-H1533. doi:10.1152/ajpheart.00844.2001

De Palma, C., Morisi, F., Cheli, S., Pambianco, S., Cappello, V., Vezzoli, M., et al. (2012). Autophagy as a new therapeutic target in Duchenne muscular dystrophy. Cell Death Dis. 3, e418. doi:10.1038/cddis.2012.159

Demontis, F., Patel, V. K., Swindell, W. R., and Perrimon, N. (2014). Intertissue control of the nucleolus via a myokine-dependent longevity pathway. Cell Rep. 7, 1481-1494. doi:10.1016/j.celrep.2014.05.001

Demontis, F., and Perrimon, N. (2009). Integration of insulin receptor/Foxo signaling and dMyc activity during muscle growth regulates body size in Drosophila. Development 136, 983-993. doi:10.1242/dev.027466

Demontis, F., and Perrimon, N. (2010). FOXO/4E-BP signaling in Drosophila muscles regulates organism-wide proteostasis during aging. Cell 143, 813-825. doi:10.1016/j.cell.2010.10.007

Demontis, F., Piccirillo, R., Goldberg, A. L., and Perrimon, N. (2013a). Mechanisms of skeletal muscle aging: insights from Drosophila and mammalian models. Dis Model. Mech. 6, 1339-1352. doi:10.1242/dmm.012559

Demontis, F., Piccirillo, R., Goldberg, A. L., and Perrimon, N. (2013b). The influence of skeletal muscle on systemic aging and lifespan. Aging Cell 12, 943-949. doi:10.1111/acel.12126
DeRuisseau, K. C., Kavazis, A. N., and Powers, S. K. (2005). Selective downregulation of ubiquitin conjugation cascade mRNA occurs in the senescent rat soleus muscle. Exp. Gerontol. 40, 526-531. doi:10.1016/j.exger.2005.04.005

Drummond, M. J., Fry, C. S., Glynn, E. L., Dreyer, H. C., Dhanani, S., Timmerman, K. L., et al. (2009). Rapamycin administration in humans blocks the contractioninduced increase in skeletal muscle protein synthesis. J. Physiol. 587, 1535-1546. doi:10.1113/jphysiol.2008.163816

Dubé, J. J., and Goodpaster, B. H. (2006). Assessment of intramuscular triglycerides: contribution to metabolic abnormalities. Curr. Opin. Clin. Nutr. Metab. Care 9, 553-559. doi:10.1097/01.mco.0000241664.38385.12

Edström, E.,Altun, M., Hägglund, M., and Ulfhake, B. (2006). Atrogin-1/MAFbx and MuRF1 are downregulated in ageing-related loss of skeletal muscle. J. Gerontol. A Biol. Sci. Med. Sci. 61, 663-674. doi:10.1093/gerona/61.7.663

Eghtesad, S., Jhunjhunwala, S., Little, S. R., and Clemens, P. R. (2011). Rapamycin ameliorates dystrophic phenotype in mdx mouse skeletal muscle. Mol. Med. 17, 917-924. doi:10.2119/molmed.2010.00256

Engel, A. G., and Ozawa, E. (2004). "Dystrophinopathies," in Myology, Vol. 2, eds A. W. Engel and C. Franzini-Armstrong (New York, NY: McGraw-Hill), 961-1026.

Ervasti, E., and Campbell, K. P. (1993). A role for the dystrophin-glycoprotein complex as a transmembrane linker between laminin and actin. J. Cell Biol. 122, 809-823. doi:10.1083/jcb.122.4.809

Fanin, M., Nascimbeni, A. C., and Angelini, C. (2013). Muscle atrophy in limb girdle muscular dystrophy 2A: a morphometric and molecular study. Neuropathol. Appl. Neurobiol. 39, 762-771. doi:10.1111/nan.12034

Fanin, M., Nascimbeni, A. C., and Angelini, C. (2014). Muscle atrophy, ubiquitinproteasome, and autophagic pathways in dysferlinopathy. Muscle Nerve. doi:10. 1002/mus. 24167

Fry, C. S., Drummond, M. J., Glynn, E. L., Dickinson, J. M., Gundermann, D. M., Timmerman, K. L., et al. (2011). Aging impairs contraction-induced human skeletal muscle mTORC1 signaling and protein synthesis. Skelet. Muscle 1, 11. doi:10.1186/2044-5040-1-11

Funai, K., Parkington, J. D., Carambula, S., and Fielding, R. A. (2006). Age-associated decrease in contraction-induced activation of downstream targets of Akt/mTOR signaling in skeletal muscle. Am. J. Physiol. Regul. Integr. Comp. Physiol. 290, R1080-R1086. doi:10.1152/ajpregu.00277.2005

Furuno, K., Goodman, M. N., and Goldberg, A. L. (1990). Role of different proteolytic systems in the degradation of muscle proteins during denervation atrophy. J. Biol. Chem. 265, 8550-8557.

Gan, B., Yoo, Y., and Guan, J. L. (2006). Association of focal adhesion kinase with tuberous sclerosis complex 2 in the regulation of $s 6$ kinase activation and cell growth. J. Biol. Chem. 281, 37321-37329. doi:10.1074/jbc.M605241200

Gaugler, M., Brown, A., Merrell, E., DiSanto-Rose, M., Rathmacher, J. A., and Reynolds, T. H. IV. (2011). PKB signaling and atrogene expression in skeletal muscle of aged mice. J. Appl. Physiol. 111, 192-199. doi:10.1152/japplphysiol. 00175.2011

Gauthier-Rouviére, C., Vandromme, M., Tuil, D., Lautredou, N., Morris, M., Soulez, M., et al. (1996). Expression and activity of serum response factor is required for expression of the muscle-determining factor MyoD in both dividing and differentiating mouse C2C12 myoblasts. Mol. Biol. Cell 7, 719-729. doi:10.1091/mbc.7.5.719

Gazzerro, E., Assereto, S., Bonetto, A., Sotgia, F., Scarfi, S., Pistorio, A., et al. (2010). Therapeutic potential of proteasome inhibition in Duchenne and Becker muscular dystrophies. Am. J. Pathol. 176, 1863-1877. doi:10.2353/ajpath.2010. 090468

Gentry, B. A., Ferreira, J. A., Phillips, C. L., and Brown, M. (2011). Hindlimb skeletal muscle function in myostatin-deficient mice. Muscle Nerve 43, 49-57. doi:10.1002/mus. 21796

Glass, D. J. (2010). PI3 kinase regulation of skeletal muscle hypertrophy and atrophy. Curr. Top. Microbiol. Immunol. 346, 267-278. doi:10.1007/82_2010_78

Gordon, S. E., Flück, M., and Booth, F. W. (2001). Selected contribution: skeletal muscle focal adhesion kinase, paxillin, and serum response factor are loading dependent. J. Appl. Physiol. 90, 1174-1183.

Grumati, P., Coletto, L., Sabatelli, P., Cescon, M., Angelin, A., Bertaggia, E., et al. (2010). Autophagy is defective in collagen VI muscular dystrophies, and its reactivation rescues myofiber degeneration. Nat. Med. 16, 1313-1320. doi:10.1038/ nm. 2247 
Guerci, A., Lahoute, C., Hébrard, S., Collard, L., Graindorge, D., Favier, M., et al. (2012). Srf-dependent paracrine signals produced by myofibers control satellite cell-mediated skeletal muscle hypertrophy. Cell Metab. 15, 25-37. doi:10.1016/j.cmet.2011.12.001

Gurpur, P. B., Liu, J., Burkin, D. J., and Kaufman, S. J. (2009). Valproic acid activates the PI3K/Akt/mTOR pathway in muscle and ameliorates pathology in a mouse model of Duchenne muscular dystrophy. Am. J. Pathol. 174, 999-1008. doi:10.2353/ajpath.2009.080537

Haddad, F., and Adams, G. R. (2006). Aging-sensitive cellular and molecular mechanisms associated with skeletal muscle hypertrophy. J. Appl. Physiol. 100, 1188-1203. doi:10.1152/japplphysiol.01227.2005

Hauerslev, S., Sveen, M. L., Vissing, J., and Krag, T. O. (2013). Protein turnover and cellular stress in mildly and severely affected muscles from patients with limb girdle muscular dystrophy type 2I. PLoS ONE 8:e66929. doi:10.1371/journal. pone.0066929

Helbling-Leclerc, A., Zhang, X., Topaloglu, H., Cruaud, C., Tesson, F., Weissenbach, J., et al. (1995). Mutations in the laminin alpha 2-chain gene (LAMA2) cause merosin-deficient congenital muscular dystrophy. Nat. Genet. 11, 216-218. doi:10.1038/ng1095-216

Hepple, R. T. (2012). Muscle atrophy is not always sarcopenia. J. Appl. Physiol. 113, 677-679. doi:10.1152/japplphysiol.00304.2012

Hoffman, E. P., Brown, R. H. Jr, and Kunkel, L. M. (1990). Dystrophin: the protein product of the Duchenne muscular dystrophy locus. Cell 51, 919-928. doi:10.1016/0092-8674(87)90579-4

Hornberger, T. A., McLoughlin, T. J., Leszczynski, J. K., Armstrong, D. D., Jameson, R. R., Bowen, P. E., et al. (2003). Selenoprotein-deficient transgenic mice exhibit enhanced exercise-induced muscle growth. J. Nutr. 133, 3091-3097.

Hwee, D. T., Baehr, L. M., Philp, A., Baar, K., and Bodine, S. C. (2014). Maintenance of muscle mass and load-induced growth in muscle RING finger 1 null mice with age. Aging Cell 13, 92-101. doi:10.1111/acel.12150

Irwin, W. A., Bergamin, N., Sabatelli, P., Reggiani, C., Megighian, A., Merlini, L., et al. (2003). Mitochondrial dysfunction and apoptosis in myopathic mice with collagen VI deficiency. Nat. Genet. 35, 361-371. doi:10.1038/ng1270

Jogo, M., Shiraishi, S., and Tamura, T. A. (2009). Identification of MAFbx as a myogenin-engaged F-box protein in SCF ubiquitin ligase. FEBS Lett. 583, 2715-2719. doi:10.1016/j.febslet.2009.07.033

Joulia-Ekaza, D., and Cabello, G. (2007). The myostatin gene: physiology and pharmacological relevance. Curr. Opin. Pharmacol. 7, 310-315. doi:10.1016/j.coph. 2006.11.011

Kanda, K., and Hashizume, K. (1989). Changes in properties of the medial gastrocnemius motor units in aging rats. J. Neurophysiol. 61, 737-746.

Keira, Y., Noguchi, S., Kurokawa, R., Fujita, M., Minami, N., Hayashi, Y. K., et al. (2007). Characterization of lobulated fibers in limb girdle muscular dystrophy type 2A by gene expression profiling. Neurosci. Res. 57, 513-521. doi:10.1016/j.neures.2006.12.010

Kim, J., Kim, Y. C., Fang, C., Russell, R. C., Kim, J. H., Fan, W., et al. (2013). Differential regulation of distinct Vps34 complexes by AMPK in nutrient stress and autophagy. Cell 152, 290-303. doi:10.1016/j.cell.2012.12.016

Kimball, S. R., O’Malley, J. P., Anthony, J. C., Crozier, S. J., and Jefferson, L. S. (2004). Assessment of biomarkers of protein anabolism in skeletal muscle during the life span of the rat: sarcopenia despite elevated protein synthesis. Am. J. Physiol. Endocrinol. Metab. 287, E772-E780. doi:10.1152/ajpendo.00535. 2003

Krag, T. O., Hauerslev, S., Sveen, M. L., Schwartz, M., and Vissing, J. (2011). Level of muscle regeneration in limb-girdle muscular type 2I relates to genotype and clinical severity. Skelet. Muscle 1, 31. doi:10.1186/2044-5040-1-31

Kroemer, G., Marino, G., and Levine, B. (2010). Autophagy and the integrated stress response. Mol. Cell 40, 280-293. doi:10.1016/j.molcel.2010.09.023

Kuwahara, K., Barrientos, T., Pipes, G. C., Li, S., and Olson, E. N. (2005). Muscle-specific signaling mechanism that links actin dynamics to serum response factor. Mol. Cell. Biol. 25, 3173-3181. doi:10.1128/MCB.25.8.31733181.2005

Kuwahara, K., Teg Pipes, G. C., McAnally, J., Richardson, J. A., Hill, J. A., BasselDuby, R., et al. (2007). Modulation of adverse cardiac remodeling by STARS, a mediator of MEF2 signaling and SRF activity. J. Clin. Invest. 117, 1324-1334. doi:10.1172/JCI31240
Kwak, K. S., Zhou, X., Solomon, V., Baracos, V. E., Davis, J., Bannon, A. W., et al. (2004). Regulation of protein catabolism by muscle-specific and cytokineinducible ubiquitin ligases E3alpha-II during cancer cachexia. Cancer Res. 64, 8193-8198. doi:10.1158/0008-5472.CAN-04-2102

Lagirand-Cantaloube, J., Cornille, K., Csibi, A., Batonet-Pichon, S., Leibovitch, M. P., and Leibovitch, S. A. (2009). Inhibition of atrogin-1/MAFbx mediated MyoD proteolysis prevents skeletal muscle atrophy in vivo. PLoS ONE 4:e4973. doi:10.1371/journal.pone.0004973

Lagirand-Cantaloube, J., Offner, N., Csibi, A., Leibovitch, M. P., Batonnet-Pichon, S., Tintignac, L. A., et al. (2008). The initiation factor eIF3-f is a major target for atrogin1/MAFbx function in skeletal muscle atrophy. EMBO J. 27, 1266-1276. doi:10.1038/emboj.2008.52

Lahoute, C., Sotiropoulos, A., Favier, M., Guillet-Deniau, I., Charvet, C., Ferry, A., et al. (2008). Premature aging in skeletal muscle lacking serum response factor. PLoS ONE 3:e3910. doi:10.1371/journal.pone.0003910

Lai, K. M., Gonzalez, M., Poueymirou, W. T., Kline, W. O., Na, E., Zlotchenko, E., et al. (2004). Conditional activation of akt in adult skeletal muscle induces rapid hypertrophy. Mol. Cell. Biol. 24, 9295-9304. doi:10.1128/MCB.24.21.9295-9304. 2004

Lamon, S., Wallace, M. A., Léger, B., and Russell, A. P. (2009). Regulation of STARS and its downstream targets suggest a novel pathway involved in human skeletal muscle hypertrophy and atrophy. J. Physiol. 587, 1795-1803. doi:10.1113/ jphysiol.2009.168674

Lange, S., Xiang, F., Yakovenko, A., Vihola, A., Hackman, P., Rostkova, E., et al. (2005). The kinase domain of titin controls muscle gene expression and protein turnover. Science 308, 1599-1603. doi:10.1126/science.1110463

Laure, L., Suel, L., Roudaut, C., Bourg, N., Ouali, A., Bartoli, M., et al. (2009). Cardiac ankyrin repeat protein is a marker of skeletal muscle pathological remodeling. FEBS J. 276, 669-684. doi:10.1111/j.1742-4658.2008.06814.x

LeBrasseur, N. K., Schelhorn, T. M., Bernardo, B. L., Cosgrove, P. G., Loria, P. M., and Brown, T. A. (2009). Myostatin inhibition enhances the effects on performance and metabolic outcomes in aged mice. J. Gerontol. A Biol. Sci. Med. Sci. 64, 940-948. doi:10.1093/gerona/glp068

Lecker, S. H., Jagoe, R. T., Gilbert, A., Gomes, M., Baracos, V., Bailey, J., et al. (2004). Multiple types of skeletal muscle atrophy involve a common program of changes in gene expression. FASEB J. 18, 39-51. doi:10.1096/fj.03-0610com

Lee, S. J. (2004). Regulation of muscle mass by myostatin. Annu. Rev. Cell Dev. Biol. 20, 61-86. doi:10.1146/annurev.cellbio.20.012103.135836

Léger, B., Derave, W., De Bock, K., Hespel, P., and Russell, A. P. (2008). Human sarcopenia reveals an increase in SOCS-3 and myostatin and a reduced efficiency of Akt phosphorylation. Rejuvenation Res. 11, 163-175. doi:10.1089/rej.2007.0588

Levine, B., and Kroemer, G. (2008). Autophagy in the pathogenesis of disease. Cell 132, 27-42. doi:10.1016/j.cell.2007.12.018

Lexell, J. (1995). Human aging, muscle mass, and fiber type composition. J. Gerontol. A Biol. Sci. Med. Sci. 50, 11-16.

Li, H. H., Kedar, V., Zhang, C., McDonough, H., Arya, R., Wang, D. Z., et al. (2004). Atrogin-1/muscle atrophy F-box inhibits calcineurin-dependent cardiac hypertrophy by participating in an SCF ubiquitin ligase complex. J. Clin. Invest. 114, 1058-1071. doi:10.1172/JCI200422220

Lokireddy, S., Wijesoma, I. W., Sze, S. K., McFarlane, C., Kambadur, R., and Sharma, M. (2012). Identification of atrogin-1-targeted proteins during the myostatininduced skeletal muscle wasting. Am. J. Physiol. Cell Physiol. 303, C512-C529. doi:10.1152/ajpcell.00402.2011

Mammucari, C., Milan, G., Romanello, V., Masiero, E., Rudolf, R., Del Piccolo, P., et al. (2007). FoxO3 controls autophagy in skeletal muscle in vivo. Cell Metab. 6, 458-471. doi:10.1016/j.cmet.2007.11.001

Marini, J. F., Pons, F., Leger, J., Loffreda, N., Anoal, M., Chevallay, M., et al. (1991). Expression of myosin heavy chain isoforms in Duchenne muscular dystrophy patients and carriers. Neuromuscul. Disord. 1, 397-409. doi:10.1016/09608966(91)90003-B

Masiero, E., Agatea, L., Mammucari, C., Blaauw, B., Loro, E., Komatsu, M., et al. (2009). Autophagy is required to maintain muscle mass. Cell Metab. 10, 507-515. doi:10.1016/j.cmet.2009.10.008

McFarlane, C., Plummer, E., Thomas, M., Hennebry, A., Ashby, M., Ling, N., et al. (2006). Myostatin induces cachexia by activating the ubiquitin proteolytic system through an NF-kappaB-independent, FoxO1-dependent mechanism. J. Cell. Physiol. 209, 501-514. doi:10.1002/jcp.20757 
McKay, B. R., Ogborn, D. I., Bellamy, L. M., Tarnopolsky, M. A., and Parise, G. (2012). Myostatin is associated with age-related human muscle stem cell function. FASEB J. 26, 2509-2521. doi:10.1096/fj.11-198663

McMullen, C. A., Ferry, A. L., Gamboa, J. L., Andrade, F. H., and DupontVersteegden, E. E. (2009). Age-related changes of cell death pathways in rat extraocular muscle. Exp. Gerontol. 44, 420-425. doi:10.1016/j.exger.2009. 03.006

Melton, L. J. III, Khosla, S., Crowson, C. S., O’Connor, M. K., O’Fallon, W. M., and Riggs, B. L. (2000). Epidemiology of sarcopenia. J. Am. Geriatr. Soc. 48, 625-630.

Mendias, C. L., Bakhurin, K. I., and Faulkner, J. A. (2008). Tendons of myostatindeficient mice are small, brittle, and hypocellular. Proc. Natl. Acad. Sci. U.S.A 105, 388-393. doi:10.1073/pnas.0707069105

Miano, J. M. (2010). Role of serum response factor in the pathogenesis of disease. Lab. Invest. 90, 1274-1284. doi:10.1038/labinvest.2010.104

Minetti, C., Sotgia, F., Bruno, C., Scartezzini, P., Broda, P., Bado, M., et al. (1998) Mutations in the caveolin-3 gene cause autosomal dominant limb-girdle muscular dystrophy. Nat. Genet. 18, 365-368.

Miralles, F., Posern, G., Zaromytidou, A. I., and Treisman, R. (2003). Actin dynamics control SRF activity by regulation of its coactivator MAL. Cell 113, 329-342. doi:10.1016/S0092-8674(03)00278-2

Mizushima, N., and Komatsu, M. (2011). Autophagy: renovation of cells and tissues. Cell 147, 728-741. doi:10.1016/j.cell.2011.10.026

Mokalled, M. H., Johnson, A. N., Creemers, E. E., and Olson, E. N. (2012). MASTR directs MyoD-dependent satellite cell differentiation during skeletal muscle regeneration. Genes Dev. 26, 190-202. doi:10.1101/gad.179663.111

Morissette, M. R., Cook, S. A., Buranasombati, C., Rosenberg, M. A., and Rosenzweig, A. (2009). Myostatin inhibits IGF-I-induced myotube hypertrophy through Akt. Am. J. Physiol. Cell Physiol. 297, C1124-C1132. doi:10.1152/ajpcell.00043.2009

Mouisel, E., Vignaud, A., Hourdé, C., Butler-Browne, G., and Ferry, A. (2010). Muscle weakness and atrophy associated with decreased regenerative capacity and changes in mTOR signaling in skeletal muscles of venerable (18-24-month-old) dystrophic mdx mice. Muscle Nerve 41, 809-818. doi:10.1002/mus.21624

Murphy, K. T., Koopman, R., Naim, T., Léger, B., Trieu, J., Ibebunjo, C., et al. (2010). Antibody-directed myostatin inhibition in 21-mo-old mice reveals novel roles for myostatin signaling in skeletal muscle structure and function. FASEB J. 24, 4433-4442. doi:10.1096/fj.10-159608

Neel, B. A., Lin, Y., and Pessin, J. E. (2013). Skeletal muscle autophagy: a new metabolic regulator. Trends Endocrinol. Metab. 24, 635-643. doi:10.1016/j.tem.2013. 09.004

Nogalska, A., D’Agostino, C., Terracciano, C., Engel, W. K., and Askanas, V. (2010) Impaired autophagy in sporadic inclusion-body myositis and in endoplasmic reticulum stress-provoked cultured human muscle fibers. Am. J. Pathol. 177, 1377-1387. doi:10.2353/ajpath.2010.100050

Ochala, J., Gustafson, A. M., Diez, M. L., Renaud, G., Li, M., Aare, S., et al. (2011). Preferential skeletal muscle myosin loss in response to mechanical silencing in a novel rat intensive care unit model: underlying mechanisms. J. Physiol. 589, 2007-2026. doi:10.1113/jphysiol.2010.202044

Ohsawa, Y., Hagiwara, H., Nakatani, M., Tasue, A., Moriyama, K., Murakami, T., et al. (2006). Muscular atrophy of caveolin-3-deficient mice is rescued by myostatin inhibition. J. Clin. Invest. 11, 2924-2934. doi:10.1172/JCI28520

Ohsawa, Y., Okada, T., Kuga, A., Hayashi, S., Murakami, T., Tsuchida, K., et al. (2008). Caveolin-3 regulates myostatin signaling. Mini-review. Acta Myol. 27, 19-24.

Paco, S., Ferrer, I., Jou, C., Cusi, V., Corbera, J., Torner, F., et al. (2012). Muscle fiber atrophy and regeneration coexist in collagen VI-deficient human muscle: role of calpain-3 and nuclear factor-кB signaling. J. Neuropathol. Exp. Neurol. 71, 894-906.

Pallafacchina, G., Calabria, E., Serrano, A. L., Kalhovde, J. M., and Schiaffino, S. (2002). A protein kinase B-dependent and rapamycin-sensitive pathway controls skeletal muscle growth but not fiber type specification. Proc. Natl. Acad. Sci. U.S.A. 99, 9213-9218. doi:10.1073/pnas.142166599

Park, C., and Cuervo, A. M. (2013). Selective autophagy: talking with the UPS. Cell Biochem. Biophys. 67, 3-13. doi:10.1007/s12013-013-9623-7

Parkington, J. D., LeBrasseur, N. K., Siebert, A. P., and Fielding, R. A. (2004). Contraction-mediated mTOR, p70S6K, and ERK1/2 phosphorylation in aged skeletal muscle. J. Appl. Physiol. 97, 243-248. doi:10.1152/japplphysiol.01383. 2003
Patel, V. K., and Demontis, F. (2014). GDF11/myostatin and aging. Aging 6, 351-352.

Patterson, M. F., Stephenson, G. M., and Stephenson, D. G. (2006). Denervation produces different single fiber phenotypes in fast- and slow-twitch hindlimb muscles of the rat. Am. J. Physiol. Cell Physiol. 291, C518-C528. doi:10.1152/ajpcell.00013.2006

Pipes, G. C., Creemers, E. E., and Olson, E. N. (2006). The myocardin family of transcriptional coactivators: versatile regulators of cell growth, migration, and myogenesis. Genes Dev. 20, 1545-1556. doi:10.1101/gad.1428006

Polge, C., Heng, A. E., Jarzaguet, M., Ventadour, S., Claustre, A., Combaret, L., et al. (2011). Muscle actin is polyubiquitinylated in vitro and in vivo and targeted for breakdown by the E3 ligase MuRF1. FASEB J. 25, 3790-3802. doi:10.1096/fj.11-180968

Puchner, E. M., Alexandrovich, A., Kho, A. L., Hensen, U., Schäfer, L. V., Brandmeier, B., et al. (2008). Mechanoenzymatics of titin kinase. Proc. Natl. Acad. Sci. U.S.A. 105, 13385-13389. doi:10.1073/pnas.0805034105

Raben, N., Hill, V., Shea, L., Takikita, S., Baum, R., Mizushima, N., et al. (2008). Suppression of autophagy in skeletal muscle uncovers the accumulation of ubiquitinated proteins and their potential role in muscle damage in Pompe disease. Hum. Mol. Genet. 17, 3897-3908. doi:10.1093/hmg/ddn292

Rahnert, J. A., Luo, Q., Balog, E. M., Sokoloff, A. J., and Burkholder, T. J. (2011). Changes in growth-related kinases in head, neck and limb muscles with age. Exp. Gerontol. 46, 282-291. doi:10.1016/j.exger.2010.11.004

Ramos, F. J., Chen, S. C., Garelick, M. G., Dai, D. F., Liao, C. Y., Schreiber, K. H., et al. (2012). Rapamycin reverses elevated mTORC1 signaling in lamin A/C-deficient mice, rescues cardiac and skeletal muscle function, and extends survival. Sci. Transl. Med. 4, 144ra103. doi:10.1126/scitranslmed.3003802

Ratkevicius, A., Joyson, A., Selmer, I., Dhanani, T., Grierson, C., Tommasi, A. M., et al. (2011). Serum concentrations of myostatin and myostatin-interacting proteins do not differ between young and sarcopenic elderly men. J. Gerontol. A Biol. Sci. Med. Sci. 66, 620-626. doi:10.1093/gerona/glr025

Rosenberg, I. (1989). Summary comments. Am. J. Clin. Nutr. 50, 1231-1233.

Roubenoff, R., and Hughes, V. A. (2000). Sarcopenia: current concepts. J. Gerontol. A Biol. Sci. Med. Sci. 55, M716-M724. doi:10.1093/gerona/55.12.M716

Rudolf, R., Khan, M. M., Labeit, S., and Deschenes, M. R. (2014). Degeneration of neuromuscular junction in age and dystrophy. Front. Aging Neurosci. 6:99. doi:10.3389/fnagi.2014.00099

Saenz, A., Azpitarte, M., Armananzas, R., Leturcq, F., Alzualde, A., Inza, I., et al. (2008). Gene expression profiling in limb girdle muscular dystrophy 2A. PLoS ONE 3:e3750. doi:10.1371/journal.pone.0003750

Sakamoto, K., Hirshman, M. F., Aschenbach, W. G., and Goodyear, L. J. (2002). Contraction regulation of Akt in rat skeletal muscle. J. Biol. Chem. 277, 11910-11917. doi:10.1074/jbc.M112410200

Sakuma, K., Akiho, M., Nakashima, H., Akima, H., and Yasuhara, M. (2008). Agerelated reductions in expression of serum response factor and myocardin-related transcription factor A in mouse skeletal muscles. Biochim. Biophys. Acta 1782, 453-461. doi:10.1016/j.bbadis.2008.03.008

Sakuma, K., Aoi, W., and Yamaguchi, A. (2014). Current understanding of sarcopenia: possible candidates modulating muscle mass. Pflugers Arch. doi:10.1007/ s00424-014-1527-x

Sakuma, K., Nakao, R., Inashima, S., Hirata, M., Kubo, T., and Yasuhara, M. (2004). Marked reduction of focal adhesion kinase, serum response factor and myocyte enhancer factor $2 \mathrm{C}$, but increase in RhoA and myostatin in the hindlimb dy mouse muscles. Acta Neuropathol. 198, 241-249. doi:10.1007/s00401-0040884-5

Sakuma, K., Nishikawa, J., Nakao, R., Nakano, H., Sano, M., Watanabe, K., et al. (2003). Serum response factor plays an important role in the mechanically overloaded plantaris muscle of rats. Histochem. Cell Biol. 119, 149-160. doi:10.1007/s00418-003-0499-2

Sakuma, K., Watanabe, K., Hotta, N., Koike, T., Ishida, K., Katayama, K., et al. (2009). The adaptive response in several mediators linked with hypertrophy and atrophy of skeletal muscle after lower limb unloading in humans. Acta Physiol. 197, 151-159. doi:10.1111/j.1748-1716.2009.01995.x

Sakuma, K., and Yamaguchi, A. (2010). Molecular mechanisms in aging and current strategies to counteract sarcopenia. Curr. Aging Sci. 3, 90-101. doi:10.2174/ 1874609811003020090 
Sakuma, K., and Yamaguchi, A. (2011a). "Sarcopenia: molecular mechanisms and current therapeutic strategy," in Cell Aging, eds J. W. Perloft and A. H. Wong (New York, NY: Nova Science Publisher), 93-152.

Sakuma, K., and Yamaguchi, A. (2011b). Inhibitors of myostatin- and proteasomedependent signaling for attenuating muscle wasting. Recent Pat. Regen. Med. 1, 284-298.

Sakuma, K., and Yamaguchi, A. (2012a). "Serum response factor (SRF)-dependent pathway: potential mediators of skeletal muscle growth and development," in Recent Res. Devel. Life. Sci, 5th Edn, ed. S. G. Pandalai (Kerala, India: Research Signpost), 13-37.

Sakuma, K., and Yamaguchi, A. (2012b). "Cellular and molecular mechanisms regulating the hypertrophy and atrophy of skeletal muscle," in Skeletal Muscle: Physiology, Classification, and Disease, ed. M. Willems (New York, NY: Nova Science Publisher), 141-194.

Sakuma, K., and Yamaguchi, A. (2012c). Sarcopenia and cachexia: the adaptation of negative regulators of skeletal muscle mass. J. Cachexia Sarcopenia Muscle 3 77-94. doi:10.1007/s13539-011-0052-4

Sakuma, K., and Yamaguchi, A. (2013a). Serum response factor (SRF)-dependent signaling in regenerating, hypertrophied, and pathological skeletal muscle. Front. Pathol. Genet. 1:1-8.

Sakuma, K., and Yamaguchi, A. (2013b). "An overview of the therapeutic strategies for preventing sarcopenia," in Basic Biology and Current Understanding of Skeletal Muscle, ed. K. Sakuma (New York, NY: Nova Science Publisher), 87-122.

Sandri, M. (2008). Signaling in muscle atrophy and hypertrophy. Physiology 23, 160-170. doi:10.1152/physiol.00041.2007

Sandri, M. (2010). Autophagy in health and disease. 3. Involvement of autophagy in muscle atrophy. Am. J. Physiol. Cell Physiol. 298, C1291-C1297. doi:10.1152/ ajpcell.00531.2009

Sandri, M. (2011). New findings of lysosomal proteolysis in skeletal muscle. Curr. Opin. Clin. Nutr. Metab. Care 14, 223-229. doi:10.1097/MCO 0b013e3283457a75

Sandri, M., Barberi, L., Bijlsma, A. Y., Blaauw, B., Dyar, K. A., Milan, G., et al. (2013). Signaling pathways regulating muscle mass in ageing skeletal muscle. The role of IGF-1-Akt-mTOR-FoxO pathway. Biogerontology 14, 303-323. doi:10.1007/s10522-013-9432-9

Shaid, S., Brandts, C. H., Serve, H., and Dikic, I. (2013). Ubiquitination and selective autophagy. Cell Death Differ. 20, 21-30. doi:10.1038/cdd.2012.72

Shefer, G., Van de Mark, D. P., Richardson, J. B., and Yablonka-Reuveni, Z. (2006). Satellite-cell pool size does matter: defining the myogenic potency of aging skeletal muscle. Dev. Biol. 294, 50-66. doi:10.1016/j.ydbio.2006.02.022

Short, K. R., Vittone, J. L., Bigelow, M. L., Proctor, D. N., and Nair, K. S. (2004). Age, and aerobic exercise training effects on whole body and muscle protein metabolism. Am. J. Physiol. Endocrinol. Metab. 286, E92-E101. doi:10.1152/ajpendo.00366.2003

Siriett, V., Platt, L., Salerno, M. S., Ling, N., Kambadur, R., and Sharma, M. (2006) Prolonged absence of myostatin reduces sarcopenia. J. Cell. Physiol. 209, 866-873. doi: $10.1002 /$ jcp. 20778

Spencer, J. A., Eliazer, S., Ilaria, R. L. Jr, Richardson, J. A., and Olson, E. N. (2000). Regulation of microtubule dynamics and myogenic differentiation by MURF, a striated muscle RING-finger protein. J. Cell Biol. 150, 771-784. doi:10.1083/jcb.150.4.771

Staron, R. S., Leonardi, M. J., Karapondo, D. L., Malicky, E. S., Falkel, J. E., Hagerman F. C., et al. (1991). Strength and skeletal muscle adaptations in heavy-resistancetrained women after detraining and retraining. J. Appl. Physiol. 70, 631-640.

Taniguchi, M., Kurahashi, H., Noguchi, S., Fukudome, T., Okinaga, T., Tsukarhara T., et al. (2006). Aberrant neuromuscular junctions and delayed terminal muscle fiber maturation in alpha-dystroglycanopathies. Hum. Mol. Genet. 15, 1279-1289. doi:10.1093/hmg/ddl045

ten Houten, R., and De Visser, M. (1984). Histopathological findings in Beckertype muscular dystrophy. Arch. Neurol. 41, 729-733. doi:10.1001/archneur.1984. 04050180051017

Terman, A., and Brunk, U. T. (2006). Oxidative stress, accumulation of biological "garbage", and aging. Antioxid. Redox Signal. 8, 197-204. doi:10.1089/ars.2006.8. 197

Thomson, D. M., and Gordon, S. E. (2006). Impaired overload-induced muscle growth is associated with diminished translational signaling in aged rat fast-twitch skeletal muscle. J. Physiol. 574, 291-305. doi:10.1113/jphysiol.2006. 107490
Tkatchenko, A. V., Le Cam, G., Léger, J. J., and Dechesne, C. A. (2000). Large-scale analysis of differential gene expression in the hindlimb muscles and diaphragm of mdx mouse. Biochim. Biophys. Acta 1500, 17-30. doi:10.1016/S0925-4439(99) 00084- 8

Trendelenburg, A. U., Meyer, A., Rohner, D., Boyle, J., Hatakeyama, S., and Glass, D. J. (2009). Myostatin reduces Akt/TORC1/p70S6K signaling, inhibiting myoblast differentiation and myotube size. Am. J. Physiol. Cell Physiol. 296, C1258-C1270. doi:10.1152/ajpcell.00105.2009

Tseng, B. S., Zhao, P., Pattison, J. S., Gordon, S. E., Granchelli, J. A., Madsen, R. W., et al. (2002). Regenerated mdx mouse skeletal muscle shows differential mRNA expression. J. Appl. Physiol. 93, 537-545. doi:10.1152/japplphysiol.00202.2002

Vainshtein, A., Grumati, P., Sandri, M., and Bonaldo, P. (2014). Skeletal muscle, autophagy, and physical activity: the ménage á trois of metabolic regulation in health and disease. J. Mol. Med. 92, 127-137. doi:10.1007/s00109-013-1096-Z

Vainzof, M., Ayub-Guerrieri, D., Onofre, P. C., Martins, P. C., Lopes, V. F., Zilberztajn, D., et al. (2008). Animal models for genetic neuromuscular diseases. J. Mol. Neurosci. 34, 241-248. doi:10.1007/s12031-007-9023-9

Vergne, I., Roberts, E., Elmaoued, R. A., Tosch, V., Delgado, M. A., ProikasCezanne, T., et al. (2009). Control of autophagy initiation by phosphoinositide 3-phosphatase Jumpy. EMBO J. 28, 2244-2258. doi:10.1038/emboj.2009.159

von Haehling, S., Morley, J. E., and Anker, S. D. (2010). An overview of sarcopenia: facts and numbers on prevalence and clinical impact. J. Cachexia Sarcopenia Muscle 1, 129-133. doi:10.1007/s13539-010-0014-2

von Maltzahn, J., Renaud, J.-M., Parise, G., and Rudnicki, A. (2012). Wnt7a treatment ameliorates muscular dystrophy. Proc. Natl. Acad. Sci. U.S.A. 109, 20614-20619. doi:10.1073/pnas.1215765109

Wagner, K. R., Fleckenstein, J. L., Amato, A. A., Barohn, R. J., Bushby, K., Escolar, D. M., et al. (2008). A phase I/II trial of MYO-029 in adult subjects with muscular dystrophy. Ann. Neurol. 63, 561-571. doi:10.1002/ana.21338

Wakabayashi, H., and Sakuma, K. (2014). Comprehensive approach to sarcopenia treatment. Curr. Clin. Pharmacol. 9, 171-180. doi:10.2174/ 1574884708666131111192845

Wehling, M., Cai, B., and Tidball, J. G. (2000). Modulation of myostatin expression during modified muscle use. FASEB J. 14, 103-110.

Welle, S., Brooks, A. I., Delehanty, J. M., Needler, N., and Thornton, C. A. (2003). Gene expression profile of aging in human muscle. Physiol. Genomics 14, 149-159.

Wenz, T., Rossi, S. G., Rotundo, R. L., Spiegelman, B. M., and Moraes, C. T. (2009). Increased muscle PGC-1alpha expression protects from sarcopenia and metabolic disease during aging. Proc. Natl. Acad. Sci. U.S.A. 106, 20405-20410. doi:10.1073/pnas.0911570106

White, T. A., and LeBrasseur, N. K. (2014). Myostatin and sarcopenia: opportunities and challenges - a mini-review. Gerontology 60, 289-293. doi:10.1159/ 000356740

Whitman, S. A., Wacker, M. J., Richmond, S. R., and Godard, M. P. (2005). Contributions of the ubiquitin-proteasome pathway and apoptosis to human skeletal muscle wasting with age. Pflugers Arch. 450, 437-446. doi:10.1007/s00424-0051473-8

Whittemore, L. A., Song, K., Li, X., Aghajanian, J., Davies, M. V., Girgenrath, S., et al. (2003). Inhibition of myostatin in adult mice increases skeletal muscle mass and strength. Biochem. Biophys. Res. Commun. 300, 965-971. doi:10.1016/S0006291X(02)02953-4

Wohlgemuth, S. E., Seo, A. Y., Marzetti, E., Lees, H. A., and Leeuwenburgh, C. (2010). Skeletal muscle autophagy and apoptosis during aging: effects of calorie restriction and life-long exercise. Exp. Gerontol. 45, 138-148. doi:10.1016/j.exger.2009. 11.002

Wolfman, N. M., McPherron, A. C., Pappano, W. N., Davies, M. V., Song, K., Tomkinson, K. N., et al. (2003). Activation of latent myostatin by the BMP-1/tolloid family of metalloproteinases. Proc. Natl. Acad. Sci. U.S.A. 100, 15842-15846. doi:10.1073/pnas.2534946100

Yang, W., Zhang, Y., Li, Y., Wu, Z., and Zhu, D. (2007). Myostatin induces cyclin D1 degradation to cause cell cycle arrest through a phosphatidylinositol 3kinase/Akt/GSK-3 $\beta$ pathway and is antagonized by insulin-like growth factor 1. J. Biol. Chem. 282, 3799-3808. doi:10.1074/jbc.M610185200

Yarasheski, K. E., Bhasin, S., Sinha-Hikim, I., Pak-Loduca, J., and Gonzalez-Cadavid, N. F. (2002). Serum myostatin-immunoreactive protein is increased in 60- to 92-year-old women and men with muscle wasting. J. Nutr. Health Aging 6, 343-348. 
Yoshida, M., and Ozawa, E. (1990). Glycoprotein complex anchoring dystrophin to sarcolemma. J. Biochem. 108, 748-752.

Zanotti, S., Saredi, S., Ruggieri, A., Fabbri, M., Blasevich, F., Romaggi, S., et al. (2007). Altered extracellular matrix transcript expression and protein modulation in primary Duchenne muscular dystrophy myotubes. Matrix Biol. 26, 615-624. doi:10.1016/j.matbio.2007.06.004

Zhao, J., Brault, J. J., Schild, A., Cao, P., Sandri, M., Schiaffino, S., et al. (2007). FoxO3 coordinately activates protein degradation by the autophagic/lysosomal and proteasomal pathways in atrophying muscle cells. Cell Metab. 6, 472-483. doi:10.1016/j.cmet.2007.11.004

Zhou, J., Freeman, T. A., Ahmad, F., Shang, X., Mangano, E., Gao, E., et al. (2013). GSK-3 $\alpha$ is a central regulator of age-related pathologies in mice. J. Clin. Invest. 123, 1821-1832. doi:10.1172/JCI64398

Zoncu, R., Efeyan, A., and Sabatini, D. M. (2011). mTOR: from growth signal integration to cancer, diabetes and ageing. Nat. Rev. Mol. Cell Biol. 12, 21-35. doi: $10.1038 / \mathrm{nrm} 3025$
Conflict of Interest Statement: The authors declare that the research was conducted in the absence of any commercial or financial relationships that could be construed as a potential conflict of interest.

Received: 05 June 2014; accepted: 10 August 2014; published online: 29 August 2014. Citation: Sakuma K, Aoi W and Yamaguchi A (2014) The intriguing regulators of muscle mass in sarcopenia and muscular dystrophy. Front. Aging Neurosci. 6:230. doi: 10.3389/fnagi.2014.00230

This article was submitted to the journal Frontiers in Aging Neuroscience.

Copyright (C) 2014 Sakuma, Aoi and Yamaguchi. This is an open-access article distributed under the terms of the Creative Commons Attribution License (CC BY). The use, distribution or reproduction in other forums is permitted, provided the original author(s) or licensor are credited and that the original publication in this journal is cited, in accordance with accepted academic practice. No use, distribution or reproduction is permitted which does not comply with these terms. 